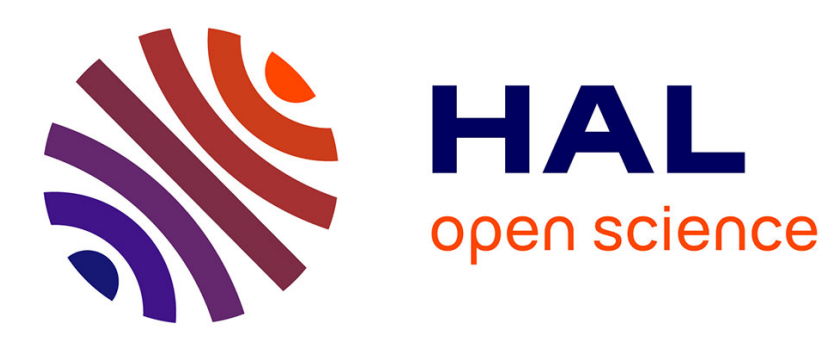

\title{
Noxious Mechanosensation
}

Patrick Delmas, Sergiy M Korogod, Bertrand Coste

\section{To cite this version:}

Patrick Delmas, Sergiy M Korogod, Bertrand Coste. Noxious Mechanosensation. The Oxford Handbook of the Neurobiology of Pain, pp.1-41, 2019, 10.1093/oxfordhb/9780190860509.013.14 . hal02346216

\section{HAL Id: hal-02346216 https://hal-amu.archives-ouvertes.fr/hal-02346216}

Submitted on 4 Nov 2019

HAL is a multi-disciplinary open access archive for the deposit and dissemination of scientific research documents, whether they are published or not. The documents may come from teaching and research institutions in France or abroad, or from public or private research centers.
L'archive ouverte pluridisciplinaire HAL, est destinée au dépôt et à la diffusion de documents scientifiques de niveau recherche, publiés ou non, émanant des établissements d'enseignement et de recherche français ou étrangers, des laboratoires publics ou privés. 


\section{Noxious Mechanosensation}

\section{Patrick DELMAS ${ }^{1 *}$, Sergiy M. KOROGOD ${ }^{2}$, Bertrand COSTE ${ }^{1}$}

${ }^{1}$ Laboratoire de Neurosciences Cognitives, LNC - UMR 7291 Aix-Marseille Université CNRS, Marseille, France

${ }^{2}$ Department of Molecular biophysics, Bogomoletz Institute of Physiology, National Academy of Sciences of Ukraine, Kyiv, Ukraine

*Corresponding author

Article title: Noxious mechanosensation

Abstract. This article introduces a number of critical features of mechanical transduction and neuronal sensory coding with particular reference to mechanical pain. High threshold mechanoreceptors (HTMRs) in skin are the first relay point for the transduction of noxious mechanical force into the nervous system and their properties determine how and when nociceptive signal is relayed up to the central nervous system. The article describes the structure and physiology of the mechano-nociceptors and explains the peripheral molecular mechanisms of transduction leading to mechanical pain. In addition, this article also describes a set of computer models of HTMRs and relevant ion channels representing structural and biophysical features of the biological prototype. A better understanding of HTMRs' function may lead to the development of novel therapeutic pathways in the treatment of chronic mechanical pain.

Keywords: pain, mechanonociception, inflammation, neuropathic pain, sensory neurons, mechanosensitive channels, piezo, Nav1.9, Kv1.1, ectopic discharges, modeling pain 


\section{Introduction on mechanical nociceptors}

Nociceptors are specialized peripheral sensory neurons that alert us to potentially damaging stimuli such as extreme temperature or pressure and that also respond to injury-related chemicals, including inflammatory mediators and toxic chemicals. Like other sensations nociception is detected, encoded, and transmitted to the central nervous system (CNS). However, while most of the sensory and somatosensory modalities are primarily informative, pain serves a protective role (Basbaum et al. 2009).

Like other sensory neurons, nociceptive neurons are pseudo-unipolar, with one axonal branch that extends to the periphery and another branch that forms synapses with second order neurons in the spinal cord. The cell soma of nociceptive neurons innervating the skin, muscle, joints, bone and viscera of the body resides para-spinally in the dorsal root ganglion (DRG), whereas sensory neurons responsible for cranial sensation have their cell bodies in the trigeminal ganglion (TG) located at the base of the cranium.

Nociceptors are classified according to the sensory modalities that activate them, i.e. thermal, chemical and mechanical. Thus, different subgroups of nociceptors have been identified, including mechano-heat, heat, mechano-heat-cold and mechano-insensitive-heat-insensitive (dubbed silent) subgroups (Kumazawa 1996; Woolf and Ma 2007). An additional distinction between nociceptors is made based on the diameter and conduction velocity of their axons (Kumazawa 1996; Djouhri and Lawson 2004). Three categories can be loosely defined based on axon characteristics: large diameter, heavily myelinated $\mathrm{A} \beta$ fibers (cross sectional area ranging from 6 to $20 \mu \mathrm{m}$ ) with fast conduction velocity (range 30 to $75 \mathrm{~m} / \mathrm{s}$ ), medium diameter, thinly myelinated $A \delta$ fibers (cross sectional area ranging from 2 to $5 \mu \mathrm{m}$ ) with conduction velocities of 
$5-30 \mathrm{~m} / \mathrm{s}$ and small diameter, unmyelinated C fibers (cross sectional area ranging from 0.3 to 3 $\mu \mathrm{m})$ with slow conduction velocity $(0.5-2 \mathrm{~m} / \mathrm{s})$. Myelinated $A \delta / \beta$ fibers carry the nociceptive input responsible for the sharp pricking pain whereas the small, unmyelinated $\mathrm{C}$ fibers carry the nociceptive input responsible for the dull aching pain. Silent nociceptors become sensitive to noxious mechanical or extreme temperature stimuli only after being sensitized by inflammatory mediators (Meyer et al. 1991). These nociceptors have small, unmyelinated C fibers that conduct impulses at a velocity of less than $3 \mathrm{~m} / \mathrm{s}$. Units responding to thermal, mechanical and chemical stimuli (i.e. polymodal) are the most common C-fiber type observed in situ.

By definition, mechanonociceptors (e.g. HTMRs) are activated by intense (i.e. noxious) mechanical stimuli that impose the risk of tissue injury. They remain silent without stimulation or under conditions of soft touch, becoming activated only after stimulation reaches a relatively high threshold. This is in contrast with the so-called low-threshold mechanoreceptors (LTMRs) that encode a continuous range of stimulus intensities below the noxious threshold (e.g. mechanoreceptors for soft touch) (Delmas et al. 2011; Abraira and Ginty 2013; Fleming and Luo 2013). The majority of thinly myelinated $\mathrm{A} \delta$ and $\mathrm{C}$ fibers are thought to be nociceptors based on responses to noxious stimuli. However, large subsets of A $\delta$ (D-hair afferents) and a particular subset of C-fibers (C-LTMRs) display thresholds well below the nociceptive range (Brown and Iggo 1967; Abraira and Ginty 2013) and respond to slow moving gentle touch such as that produced by lightly stroking the skin.

Another important property of mechanoreceptors is their capacity to adapt upon static mechanical stimulation (Delmas et al. 2011; Abraira and Ginty 2013) (Table 1). Mechanoreceptors with adaptation exhibit high-frequency firing activity at the onset of the mechanical stimulus but turn into silence during the static phase of the stimulus (e.g. rapidly adapting, RA). This phenomenon 
accounts for the perceptual adaptation in which the stimulus vanishes from consciousness. RA mechanoreceptors typically signal the velocity and acceleration of the stimulation in the nonnoxious range. A number of mechanoreceptors also activate (or re-activate) at the end of the stimulus, conveying information about the changing sensory environment to the brain. LTMRs classified as RA include the hair follicle and the Meissner and Pacini corpuscles, while those classified as slowly adapting (SA) include the Merkel cell-neurite complex and the Ruffini corpuscle (Lumpkin and Caterina 2007; Zimmerman et al. 2014). HTMRs that transmit pain and some proprioceptive sensory neurons, which sustain postural states, exhibit little or no adaptation (Lewin and Moshourab 2004; Delmas et al. 2011). HTMRs are able to signal stimulus magnitude for several minutes or hours. The stimulus duration is signaled by persistent generation of APs throughout the period of stimulation, which contributes to the persistence of pain (Table 1).

In their function as transducers of noxious stimuli, HTMRs convert mechanical force into electrical signal. At the transduction site, mechanical energy is transduced into a change in membrane potential that is called receptor/generator potential. The receptor potential is then transformed into a neural pulse code, in which the frequency of APs reflects to some extent the intensity of the stimulus. The ion channels expressed in peripheral nociceptors are directly activated by mechanical noxious stimuli, leading to nociceptor activation (Delmas et al. 2011; Delmas and Coste 2013; Ranade et al. 2015) (Fig. 1A). Surprisingly, transduction mechanisms underlying mechanical nociception are poorly understood despite clinical relevance in pain conditions such as diabetes, osteoarthritis and inflammatory diseases (Wood and Eijkelkamp 2012; Lolignier et al. 2015). With the recent cloning and functional characterization of the mechanically-activated piezo proteins (Coste et al. 2010; Coste et al. 2012; Parpaite and Coste 2017; Wu et al. 2017), the prototype of the mechanotransducer ion channels involved in soft 
touch and proprioception has been identified (Ranade et al. 2014; Woo et al. 2015; Florez-Paz et al. 2016). A major issue then is to understand how noxious information is transduced into electrical signal in nociceptors and encoded, via voltage-gated ion channels, into a neural pulse code.

Here, we review the nociceptive mechanisms of mechanical pain perception, focusing mainly on nociceptors innervating the skin. We provide an overview of how mechanical noxious stimuli are detected and encoded. Since reviews have described and discussed the biological components of both physiological and pathological pain processing (Dubin and Patapoutian 2010; Gebhart and Bielefeldt 2016; Eitner et al. 2017; Woller et al. 2017), we will focus here on the molecules potentially involved in transducing mechanical noxious stimuli and will highlight, using computational models of nociceptors, how specific ion channels may contribute to the generation of mechanical pain in healthy and sensitized conditions. Current work in this field is providing researchers with a more thorough understanding of mechanonociceptor cell biology at molecular level. A better understanding of mechanical nociception is required to develop new therapeutic strategies.

\section{Transduction of noxious mechanical stimuli}

\section{Properties of excitatory MS currents in native DRG neurons}

The challenges encountered in identifying molecular transducers of noxious mechanical stimuli include the relevance of stimulation protocols applied in cellular assays and their correlation/extrapolation with nociception and pain models. Several assays of cellular responses to mechanostimulation have been developed in recent years and have begun to uncover the molecular basis of mechanotransduction [see for review Delmas et al. (2011); Roudaut et al. (2012)]. The most widely used technique (e.g. poking, whole-cell mechano-clamp) consists in 
mechanically challenging the cell soma or neurites of isolated DRG neurons using a glass probe while recording the evoked mechanotransducer currents (McCarter et al. 1999; Drew et al. 2002; Hu and Lewin 2006; Coste et al. 2007; Hao and Delmas 2011) (Fig. 1B). Recording of isolated DRG neurons is a standard approach in sensory studies because cultured DRG neurons retain many aspects of their native properties, including sensitivity to a range of thermal and mechanical stimuli (Tominaga et al. 1998; Peier et al. 2002; Story et al. 2003; Coste et al. 2010). These experiments have helped to characterize the basic properties of MS currents in DRG neurons. Based on kinetics analysis of inactivation, three main types of MS currents have been described in DRG neurons: rapidly adapting $(\tau=2-6 \mathrm{~ms})$, intermediately adapting $(\tau=15-30 \mathrm{~ms})$ and slowly adapting/ultraslow current ( $\tau \geq 100 \mathrm{~ms}$ ) (McCarter et al. 1999; Drew et al. 2002; Coste et al. 2007; Hao and Delmas 2010; Rugiero et al. 2010) (Fig. 1C). Relative anion-cation permeability deduced from reversal potential measurements suggest a cationic non-selective permeability of these MS inward currents (McCarter et al. 1999; Drew et al. 2002; McCarter and Levine 2006; Hao and Delmas 2010). Slowly adapting/ultra slow currents are preferentially, but not exclusively, encountered in small-to-medium diameter DRG neurons with properties consistent with HTMRs or polymodal nociceptors, based on the expression of the nociceptorspecific $\mathrm{Na}^{+}$channels, Nav1.8 and Nav1.9 and the noxious heat, transient receptor potential vanilloid type 1 ion channel (TRPV1) (Drew et al. 2002; Hu and Lewin 2006; Coste et al. 2007; Drew et al. 2007; Hao and Delmas 2010; Li et al. 2011). However, a subset of nociceptors also displays MS inward currents with rapid component (Drew et al. 2002). Although relationship between in vitro and in vivo data remains speculative, these findings suggest that slowly adapting/ultraslow MS currents play a critical role in generating sustained activities of nociceptors in vivo (Hao and Delmas 2010). 
There is now compelling evidence that indicate that rapidly-adapting MS currents recorded in LTMRs from DRGs and mesencephalic trigeminal nucleus neurons are mediated by Piezo2 subunits (Coste et al. 2010; Eijkelkamp et al. 2013; Lou et al. 2013; Florez-Paz et al. 2016) (Fig. 1C). The deletion of Piezo2 abrogates rapidly-adapting currents in light touch mechanoreceptors and proprioceptors, without affecting mechanosensitivity in neurons with intermediately and slowly adapting MS currents (Ranade et al. 2014; Woo et al. 2015). TMEM150C/Tentonin3 was recently proposed to act as an ion channel mediating slowly adapting MS currents in proprioceptive neurons and in expression systems (Hong et al. 2016). However, it was recently shown that heterologous expression of TMEM150C fails to generate MS currents in cells with genomic ablation of the piezol gene (Dubin et al. 2017), suggesting that TMEM150C may be a regulator of piezo channel function rather than a pore-forming channel subunit contributing to slowly adapting MS currents.

\section{Molecular candidates of excitatory mechanotransducers in nociceptors}

TRP channels are candidates based on expression and functional similarities to evolutionary counterparts (Christensen and Corey 2007; Delmas and Coste 2013) but whether these contribute to mechanical transduction in nociceptors is still uncertain. In mammalian sensory neurons, TRP channels are best known for sensing thermal information and mediating neurogenic inflammation, and only two TRP channels, TRPA1 and TRPV4, have been directly or indirectly linked with mechanosensation.

TRPA1. The contribution of TRPA1 to mechanosensory function and mechanically-evoked pain remains unresolved due to a series of contrasting results. Consistent with its expression pattern in a subset of small DRG neurons, TRPA1 has been put forward as potential candidate to mediate slowly adapting MS currents in nociceptors. In vitro studies have shown that slowly adapting MS 
currents are absent in small-diameter DRG neurons from $\operatorname{Trpal}^{-/-}$mice, raising the possibility that TRPA1 mediates slowly adapting MS currents (Drew and Wood 2007; Kerstein et al. 2009; Vilceanu and Stucky 2010). Chemical inhibition of TRPA1 evokes subtle behavioral deficits, suggesting that TRPA1 may play a modulatory role of noxious mechanical response (Petrus et al. 2007; Lennertz et al. 2012). At variance, Rugiero and Wood (2009) ruled out a role of TRPA1 in mediating slowly adapting MS currents while another study (Brierley et al. 2011), using neurite probing, suggested that $\operatorname{Trpal}^{-/}$mice have reduced intermediately adapting MS currents in smalldiameter DRG neurons but no alteration of mechanosensory currents in other DRG neurons.

In vivo studies have shown that mice lacking TRPA1 (constitutive KO) display a higher mechanical threshold and reduced responses to supra-threshold mechanical stimuli, along with presenting reduced mechanical hyperalgesia during inflammation (Kwan et al. 2006). Recordings of skin-nerve preparations from $\operatorname{Trpal}^{-/}$mice also showed impaired firing rates of C-fiber nociceptors in response to noxious mechanical stimuli (Kwan et al. 2006). However, these conclusions have been challenged (Bautista et al. 2006). More recent experiments, using AdvillinCre-Trpal ${ }^{f l f l}$ mice with TRPA1 deletion in a majority of DRG neurons, showed mechanosensory behavior deficits, which manifested as altered responsiveness to light touch stimuli and faint impairment to noxious stimuli (Zappia et al. 2017). Thus, although there is substantial evidence for a role of TRPA1 in the sensitization of nociceptors to mechanical, thermal as well as chemical cues in vivo, its contribution as a mechanical transducer in baseline mechanosensation awaits definitive demonstration at the molecular level.

TRPV4. TRPV4 acts as an osmotransducer because, in addition to warm temperature and acidic $\mathrm{pH}$, it is activated by osmotic force-induced cell swelling and fluid shear stress. However, TRPV4 activation by swelling is indirect and requires fatty acid metabolites (Vriens et al. 2004; 
Liedtke 2005), a requirement that disqualifies TRPV4 as a genuine mechanically-activated channel. Moreover, disrupting TRPV4 expression in mice causes only modest deficits in response thresholds to a tail pinch stimulus (Liedtke et al. 2000; Suzuki et al. 2003; Vriens et al. 2004) but strongly impairs responses of nociceptive neurons to osmotic stress and inflammation (Liedtke et al. 2000; Alessandri-Haber et al. 2006).

ASIC. A role has been assigned for acid-sensitive ion channels (ASICs) in mechanosensation but there is no definite evidence it is involved in mechanotransduction. ASICs belong to a protongated subgroup of the degenerin-epithelial $\mathrm{Na}^{+}$channel family of cation channels (Waldmann and Lazdunski 1998; Lingueglia 2007). These channels were initially implicated in mechanotransduction because their phylogenetic homologues in C. elegans, the MEC subunits, are essential for perception of touch. Three members of the ASIC family (ASIC1-3) are expressed in peripheral mechanoreceptors and nociceptors in mammals. Deletion of ASIC1a does not alter the function of cutaneous mechanoreceptors but increases mechanical sensitivity of sensory afferences innervating the gut (Page et al. 2004). Knocking out ASIC2 in mice led to contrasting results, showing either decreased sensitivity of rapidly adapting cutaneous LTMRs (Price et al. 2000; Price et al. 2001) or no alteration of cutaneous mechanosensation (Roza et al. 2004). More convincingly, it was shown that ASIC2 is expressed in aortic baroreceptor neuron somata and terminals, and contributes to the baroreceptor sensitivity (Lu et al. 2009). ASIC2-null mice develop hypertension and exhibit a decreased gain of the baroreflex, suggesting that mechanosensitivity is diminished in ASIC2-null mice. ASIC3 disruption also decreases mechanosensitivity of visceral afferents and reduces responses of cutaneous HTMRs to noxious stimuli (Price et al. 2001). Unpredictably, transgenic expression of a dominant-negative form of ASIC3 leads to an increased sensitivity to noxious mechanical stimuli (Mogil et al. 2005). 
These data indicate that ASIC proteins are involved in mechanosensation in mammals, however their role as prime contender for directly transducing mechanical force in native neurons is still unresolved. In addition, we lack evidence that the channels are mechanically sensitive when expressed in heterologous cells (Garcia-Anoveros et al. 2001; Roza et al. 2004). Moreover, the ion selectivity and permeability ratios of recombinant ASICs differ from those of mechanosensitive currents recorded in native sensory neurons. Consistent with this, no differences in amplitude, kinetics or incidence of MS currents in DRG neuron somata were seen in transgenic mice lacking ASIC2 and ASIC3 (Drew et al. 2004; Lechner and Lewin 2009). Altogether, these data indicate that ASIC channels alone are not sufficient to reconstruct mechanically-activated channels, but support a modulatory role for these channels in mechanosensation in multiple systems (See Omerbasic et al. (2015) for review).

The stomatin-like protein 3, STOML3, evolutionarily related to MEC-2, has been shown to be involved in regulating innocuous touch (Wetzel et al. 2007). Loss of STOML3 increased the number of mechanically insensitive DRG nerve fibers and led to deficits in the ability of mice to sense a sandpaper-like textured surface. In addition, STOML3 can modulate the sensitivity of both Piezo1 and Piezo2 in vitro by decreasing the mechanical threshold needed for activation of these channels (Poole et al. 2014). However, genetic deletion of STOML3 in mouse does not compromise behavioral responses to noxious pressure (Wetzel et al. 2007), but STOML3 inhibitors can reverse mechanical hypersensitivity in nerve injury or diabetic neuropathy models (Wetzel et al. 2017).

PIEZO2. The discovery of Piezo channels (Coste et al. 2010), the first bona-fide mechanically activated ion channels identified in mammals (Coste et al. 2012; Syeda et al. 2016), provided promising candidates regarding mechanical pain transducers. Piezo1 is not expressed in DRG 
neurons, but Piezo2 is detected in up to $45 \%$ of total DRG neurons (Lou et al. 2013; Woo et al. 2014). In situ hybridization experiments revealed that Piezo2-expressing neurons form a heterogeneous population including large-diameter, myelinated neurons encompassing LTMRs as well as medium- and small-diameter putative nociceptors, based on peripherin- and TRPV1stainings (Coste et al. 2010). Moreover, expression of Piezo2 has also been suggested in putative mechano-nociceptors innervating the cornea (Bron et al. 2014; Alamri et al. 2015) and in mechanically-sensitive A $\delta$ nociceptors innervating the bone marrow (Nencini and Ivanusic 2017).

Conditional knock-out achieved in the majority of DRG neurons using Advil-creERT2 mice demonstrated the crucial implication of Piezo2 in innocuous light touch (Ranade et al. 2014). More specific conditional knock-out studies selectively targeting Piezo2 in proprioceptors innervating muscle spindles and Golgi tendon organs (Woo et al. 2015; Florez-Paz et al. 2016) and mesencephalic trigeminal nucleus proprioceptor neurons innervating head muscles (FlorezPaz et al. 2016), indicate that Piezo2 is the major mechanotransducer of mammalian proprioceptors. On the contrary, Piezo2 does not seem to be involved in acute mechanical pain sensing under normal conditions as Piezo2 conditional knock-out mice behave similarly to wildtype animals when assayed for mechanical pain using von Frey, tail clip or Randall Selitto assays (Ranade et al. 2014). Therefore, if Piezo2 has a function in nociceptive neurons it is not in setting the noxious mechanical threshold under normal conditions.

Growing evidences suggest that Piezo2 is involved in mechanical allodynia/hyperalgesia occurring during neuropathic or inflammatory conditions. Indeed, Piezo2 activation has been shown to be enhanced by bradykinin through PKA/PKC pathways in a subset of capsaicinsenstive DRG neurons tentatively classified as mechano-heat nociceptors (Dubin et al. 2012). 
Although Piezo2 appeared to be sensitized in response to inflammatory signals in vitro, no changes in mechanical allodynia were detected in Piezo2 conditional $\mathrm{KO}$ mice following bradykinin injection in the hind paw (Ranade et al. 2014), questioning about the target tissue(s) and the functional relevance of this neuronal subpopulation. Another study demonstrated the positive modulation of Piezo2 through the cyclic AMP sensor Epac1 pathway in large-diameter DRG neurons (Eijkelkamp et al. 2013). Knock-down of Piezo2 attenuates Epac signalingmediated mechanical allodynia, as well as allodynia induced by spinal nerve ligation or chronic constriction injury (Eijkelkamp et al. 2013). Importantly, Epac1 induced allodynia does not require Nav1.8-expressing neurons (Eijkelkamp et al. 2013), suggesting that Epac-induced mechanical allodynia involves a non-nociceptive neuronal population, which still awaits further characterization.

A recent study identified the nicotinic acetylcholine receptor subunit alpha-3 (CHRNA3) as a marker of a specific subpopulation of "silent" nociceptors (Prato et al. 2017). These neurons account for about $50 \%$ of all peptidergic nociceptive afferents innervating visceral organs and deep somatic tissues, but do not project to the skin. Remarkably, these mechanically-insensitive neurons under normal conditions display mechanically-activated Piezo2 currents upon treatments with the neurotrophin, nerve growth factor (NGF), notably involved in persistent pain states associated with inflammation (Prato et al. 2017). These data suggest a contribution of Piezo2 channels in the development of mechanical hyperalgesia in inflamed visceral organs produced by un-silencing CHRNA3-expressing nociceptors. Piezo2 contribution to visceral sensation, including acetic acid-induced hyperalgesia, has been also suggested by intrathecal Piezo2-shRNA experiments (Yang et al. 2016). Altogether these observations suggest that Piezo2 contributes to 
various types of mechanical hyperalgesia/allodynia, but its specific role in nociceptive and/or non-nociceptive sensory neuron subpopulation remains to be determined.

\section{Mechanosensitive ion channels that damp excitation}

DRG neurons express a variety of $\mathrm{K}^{+}$channels linked to mechanosensation, including members of the KCNK and Kv1 families (Alloui et al. 2006; Hao et al. 2013). The existence of these MS $\mathrm{K}^{+}$channels adds a layer of complexity to the basic model of neuronal activation by mechanical force: whereas the opening of MS cation channels leads to membrane depolarization and excitation, activation of $\mathrm{MS} \mathrm{K}^{+}$channels hyperpolarizes the membrane potential and thus decreases the likelihood of reaching AP threshold. By doing so, and assuming they open simultaneously, MS $\mathrm{K}^{+}$channels can counteract, or balance, the activity of MS excitatory channels, thereby shaping mechanosensory responses.

KCNK channels. The two-pore domain potassium (K2P, KCNK) channel family is composed by 15 genes in the human genome. Based on their primary structure, $\mathrm{K} 2 \mathrm{P}$ channels are grouped into six distinct subfamilies denoted as TREK, TALK, TASK, TWIK, THIK, and TRESK (Goldstein et al. 2005). These channels mediate $\mathrm{K}^{+}$-selective leak currents, which regulate cell excitability through their influence on resting membrane potential and are known to be modulated by a variety of factors, such as endogenous ligands, anesthetics, temperature and membrane tension (Patel et al. 1998; Maingret et al. 1999; Maingret et al. 1999; Honore 2007). Three members of the KCNK family, KCNK2 (TREK1), KCNK4 (TRAAK) and KCNK10 (TREK2), are intrinsically mechanosensitive in expression systems, and all three are expressed in DRGs (Medhurst et al. 2001; Alloui et al. 2006; Kang and Kim 2006; Noel et al. 2009). KCNK2 is found exclusively in polymodal nociceptors responsive to high pressure and extreme heat (Alloui et al. 2006). $K c n k 2^{-/-}$mice are more sensitive than wild-type mice to mechanical stimulation, 
suggesting that KCNK2 is important for tuning the mechanosensitivity of polymodal nociceptors (Alloui et al. 2006). KCNK4 is activated by both membrane stretch and membrane crenation (Maingret et al. 1999). $K c n k 4^{-/-}$mice are hypersensitive to mechanical stimulation, a phenotype that is exacerbated while additionally deleting the Kcnk2 gene (Noel et al. 2009).

One key question that remains is how mechanical forces are integrated in cells where KCNK channels are co-expressed with MS cation channels. Interestingly, Brohawn and coworkers showed that expression of KCNK4 in the neuroblastoma cell line $\mathrm{N} 2 \mathrm{~A}$ led to decreased depolarization of the membrane potential upon mechanical indentation (Brohawn et al. 2014). This effect is likely to be due to the simultaneous activation of KCNK4 channels with endogenous Piezo1, suggesting that a similar mechanism (the nature of the channel set aside) may be at play in sensory nerve endings. Despite remarkable phenotypes observed in transgenic mice, it is not yet clear whether $\mathrm{KCNK}$ channels act as mechanical transducers or as mere modulators of excitability in nociceptors.

Kv1. Although KCNK channels have attracted most attention for their MS properties, the voltage-gated $\mathrm{K}^{+}$channels of the Shaker family (Kv1) have also been linked to mechanotransduction both in vitro and in vivo. Members of the Kv1 channel family are well known to contribute to setting neuronal excitability in a variety of neurons (Coetzee et al. 1999). These channels can be divided into several subfamilies (Kv1.1, Kv1.2, Kv1.3, Kv1.4, Kv1.5 and Kv1.6) on the basis of sequence similarity and function. Recent work has shown that Kv channels made of Kv1.1 homomers or Kv1.1-Kv1.2 heteromers are mechanically-activated in DRG neurons (Hao et al. 2013). Unlike KCNK channels, which are activated by negative pressure applied through the patch pipette, Kv1.1-Kv1.2 channels are activated by indentation of the cell membrane, in addition to negative pressure applied to the patch pipette. Mechanical activation 
occurs under physiological forces $(-10 \mathrm{mmHg})$ at both macroscopic and single-channel levels, generating a slow activating/inactivating outward current. Kv1.1-containing channels retain mechanosensitivity in excised patches, indicating little contribution of cytoskeletal elements to mechanical sensitivity. Activation of Kv1.1 channels by mechanical challenge can be accounted for by a shift in the pore-opening equilibrium toward the open conformation, consistent with membrane tension acting on a late-opening transition through stabilization of a dilated pore. This effect causes a shift in the voltage range over which $\mathrm{Kv}$ channels open as well as an increase in the maximum open probability (Schmidt et al. 2012; Hao et al. 2013). Mechanistically, opening of Kv1.1 does not depend on a mechanical sensor as it has been hypothesized to be the case for the mechanically-gated piezo channels (Guo and MacKinnon 2017; Saotome et al. 2017; Zhao et al. 2018) but instead makes the best use of the inherently stretch sensitive properties of the voltage sensor (Mienville and Clay 1996; Morris and Juranka 2007; Morris 2011). Paddle chimera of drosophila Kv1.1 and Kv2.1 reconstituted in Xenopus oocytes also exhibit low threshold mechanosensitivity, indicating that tension-induced gating changes is a common property of Kv1.1 subunit-containing $\mathrm{K}^{+}$channels (Schmidt et al. 2012).

In vivo, HTMRs have been shown to be mechanically tuned by the relative expression of Kv1.11.2 and slowly adapting cation currents, whose respective inhibitory and excitatory influences modulate the net mechanical response (Hao et al. 2013). MS Kv1.1-1.2 current shifts mechanical threshold for firing towards higher values and concurrently reduces the duration of mechanicallyinduced AP discharges. Thus, the function of MS Kv1.1-1.2 in HTMRs is to tune generator potential by counteracting the action of MS excitatory channels, shifting the threshold for noxious mechano-perception to higher values. By contrast, MS Kv1.1-1.2 current has little impact on mechanical threshold properties of A $\beta$-type LTMRs because activation of Piezo 2 in 
these cells is faster than that of MS Kv1.1-1.2 current. Thus in LTMRs, Kv1.1-1.2 current does not impede detection but regulates duration and frequency of firing. Thus, functional connection between excitatory and inhibitory MS channels is important to set the properties of the receptor potential. The modulation of either component in pathological conditions may disrupt this balance and makes animals hyper- or hyposensitive to mechanical stimuli.

\section{Regulation of mechanical receptor potential by subthreshold voltage-gated channels}

The net ionic current flowing through excitatory MS channels brings membrane potential towards the threshold for triggering APs. Deviation from the resting membrane potential may therefore activate multiple intrinsic ionic conductances in the subthreshold range (Heidenreich et al. 2011; Wang and Lewin 2011; Hockley et al. 2014).

Cav3.2 calcium channel. The Cav3.2 T-type calcium channel exhibits a low threshold of activation $(\sim-60 \mathrm{mV})$ and produces $\mathrm{Ca}^{2+}$ current with rapid activation and inactivation phases in response to depolarization. Cav3.2 channels are strongly expressed in D-hair mechanoreceptors (Dubreuil et al. 2004; Coste et al. 2007; Swayne and Bourinet 2008; Wang and Lewin 2011; Hilaire et al. 2012), A $\delta$ - and C-LTMRs, innervating the skin hair follicles (Delfini et al. 2013; Francois et al. 2014) and polymodal nociceptors (Bourinet et al. 2005; Coste et al. 2007). Functional analyses indicate that Cav3.2 has a proexcitatory impact in small-diameter nociceptors expressing mechanoactivated channels (Coste et al. 2007) and favors chronic pain states. Deletion or knockdown of Cav3.2 induces a marked analgesia in vivo (Lee 2013; Francois et al. 2014). Specific knockout of Cav3.2 in C-LTMR cutaneous fibers shows that T-type $\mathrm{Ca}^{2+}$ channels determine their low threshold of mechanical activation and contribute to both mechanical and cold allodynia in peripheral neuropathy (Francois et al. 2015). These findings 
support a role for Cav3.2 in touch/pain pathophysiology, validating their pharmacological relevance to alleviate mechanical and cold allodynia.

Pharmacological inhibition as well as genetic deletion of the Cav3.2 gene in D-hair LTMRs has been shown to increase mechanical threshold and impair temporal firing (Wang and Lewin 2011). Altered properties are related to deficiency in receptor potential integration, since neither abnormal mechanotransducer current nor damaged nerve terminal structure was observed in Cav3.2 knockout mice. Thus, in D-hair mechanoreceptors, T-type calcium channels serve as subthreshold amplifier and contribute to the high sensitivity of D-hair mechanoreceptors to mechanical stimuli.

KCNQ channels. M channels, an important regulator of neural excitability, are composed of 5 subunits of the Kv7 (Kv7.1-Kv7.5) channel family (Delmas and Brown 2005). Kv7 channels are of particular interest because they are activated at subthreshold membrane potentials. Kv7.2 and Kv7.3 subunits were found to be expressed in DRG nociceptors, generating a slow $\mathrm{K}^{+}$current activated by retigabine and inhibited by XE991 (Passmore et al. 2003). KCNQ openers have demonstrated their analgesic effect in preclinical and clinical studies, and KCNQ channels are thus considered to be potential therapeutic targets as analgesics ( $\mathrm{Du}$ et al. 2017). However, their specific role in regulating mechanonociception has not been explored.

The Kv7.4 channel subunit has been found essential to tune firing activity and modulate stimulus-excitation coupling of many LTMRs. It is expressed in Meissner corpuscles, peripheral lanceolate endings, circular nerve fibers of hair follicles and in Meissner bodies (Delmas and Brown 2005; Heidenreich et al. 2011). Kv7.4 generates a low-threshold, slow activating and noninactivating current that typically regulates membrane potential (Kubisch et al. 1999). The 
presence of Kv7.4 near the mechanotransduction site suggests a role in the integration process of receptor potential. Genetic deletion of the Kcnq4 gene in mice enhances mechanosensitivity and alters frequency response of rapidly adapting LTMRs (Heidenreich et al. 2011). Human subjects with loss of function mutation of KCNQ4 outperformed control subjects when tested for vibrotactile acuity (Heidenreich et al. 2011). Thus, KCNQ4 may act as a brake on excitation of rapidly adapting LTMRs.

Nav1.9 channel. The voltage-gated Nav1.9 channel generates an atypical $\mathrm{Na}^{+}$current with hyperpolarized activation/inactivation properties, giving rise to a prominent persistent $\mathrm{Na}^{+}$ current component at subthreshold voltages (Cummins et al. 1999; Coste et al. 2004). Nav1.9 is expressed in all types of nociceptors, in which it co-localizes with slow adapting/ultraslow MS cation currents (Coste et al. 2007; Padilla et al. 2007). Nav1.9-null mice exhibit impaired mechanical and thermal sensory capacities and reduced electrical excitability of nociceptors (Hoffmann et al. 2017). Deletion of Nav1.9 in C-fibers elevates the electrical threshold of activation in single-fiber recordings and increases the von Frey mechanical threshold compared to wild type $\mathrm{C}$-fibers. Interestingly, heat threshold in $\mathrm{C}$ mechano-heat-sensitive fibers was also altered (Hoffmann et al. 2017). Thus, Nav1.9, under normal conditions, contributes to both acute thermal and mechanical nociception in mice through increasing the excitability of nociceptors and also by amplifying receptor potentials irrespective of the stimulus modality (Lolignier et al. 2015; Hoffmann et al. 2017).

Nav1.9 current plays also a crucial role upon inflammation (Rush and Waxman 2004; Maingret et al. 2008). Nav1.9 channel activity is potentiated by the concerted action of inflammatory mediators and contributes to nociceptor hyperexcitability during inflammation (Rush and Waxman 2004; Maingret et al. 2008; Vanoye et al. 2013). For that reason Nav1.9 plays a 
permissive role in the generation of mechanical pain hypersensitivity, both in subacute and chronic inflammatory pain models (Ritter et al. 2009; Lolignier et al. 2011). It is also required for normal gut mechanosensation and for the development of hypersensitivity of colonic afferents to mechanical stimuli under inflammatory conditions (Copel et al. 2013; Hockley et al. 2014). Thus, Nav1.9 endows nociceptors with a subthreshold-activating inward current that can amplify depolarizing drive induced by MS excitatory channels, a possible molecular mechanism for mechanical hyperalgesia.

\section{Modeling high threshold mechanical receptors}

Computer models provide a useful complementary tool to capture the cellular and molecular basis of noxious stimuli processing. Advantages of computational models lie in the noninvasive nature of the method and on their capabilities to predict functional consequences of ion channel modulation. The "dark side of the Moon" is that any model is a simplified representation of a prototype often based on guesses rather than on precise data. For HTMRs, the morphological structure and biophysical properties of main ion channels are relatively well established (see above). However, the data about combination of channels and their relative quantities are available mostly for the somas, but not for the peripheral and central processes. Electrical activity patterns of in vitro DRG neurons are thought to represent the nociceptor properties well enough and thus can be used for validation of computer (and conceptual) models. It is the reason why most of computer models of nociceptive neurons are the so-called "single-compartment" models of the soma (Table 2). The somatic recordings are also the main source of experimental data for the rare "multi compartment" models of DRG neurons, which include peripheral and central processes (Table 2). 


\section{Insights from models of non-mechanical C-type primary afferent neurons}

To aid in understanding the neural basis of noxious stimuli processing, computational models have focused on describing in detail the dynamics of APs and analyzing the contribution of multiple aspects (e.g. morphology, ion channels, pumps) in their generation and transmission.

Patterns of AP firing evoked by depolarizing current injections were studied in a singlecompartment model of C-fibers containing a variety of currents, including TTX-S $\mathrm{Na}^{+}$current, Kdr, T-type $\mathrm{Ca}^{2+}$ current (Cav3.1) and $\mathrm{Ca}^{2+}$-dependent $\mathrm{K}^{+}$current (SK-type, KSK), together with $\mathrm{Na}^{+} / \mathrm{K}^{+}$and $\mathrm{Ca}^{2+}$ pumps (Scriven 1981). The modeled nerve fiber generated a continuous discharge or periodical bursts of APs, depending on activity of the pumps and accumulation of current-conducting ions in the peri-axonal space (e.g. $\mathrm{K}^{+}$) and cytoplasm (e.g. $\mathrm{Na}^{+}$). An insightful point here is that any site of $\mathrm{C}$-fiber containing such cocktail of channels and pumps can become a source of continuous spiking or bursting activity.

Unmyelinated C-fibers that convey pain information usually fire at rates $<20 \mathrm{~Hz}$. How C-fiber firing is influenced by the morphology of the T-junction and the local expression of ion channels is important for understanding normal pain signaling. Sundt et al (2015) used computational modeling to investigate the interaction of axonal morphology, somatic and axonal excitability, and membrane conductances on spike conduction through the DRGs. Using a computer model in which the voltage-gated $\mathrm{Nav}$ and $\mathrm{Kdr}$ channels were present with the same density in all compartments, except at the soma, the model demonstrated that propagation reliability for single spikes was highly sensitive to the diameter of the stem axon and the density of voltage-gated $\mathrm{Na}^{+}$ channels. The short AP refractory period provided by Nav and Kdr channels allows the modeled fiber to conduct trains of spikes up to frequencies of $110 \mathrm{~Hz}$. However, the presence of Kv7 and 
the small-conductance (SK)-like $\mathrm{Ca}^{2+}$-dependent $\mathrm{K}^{+}$channels are required to reduce the firing frequency to near physiological levels found in vivo. Altogether, these simulations demonstrate that the complex interplay of ion channels and temporal gating dynamics determines the specific firing pattern of C-type nociceptors.

Other models disclose the specific roles of Nav channel subunits in C-nociceptor activity under normal and pathological conditions (Herzog et al. 2001). Recordings from small DRG neurons were used to fit parameters of simulated currents, including fast inactivating TTX-S Na${ }^{+}$current, Nav1.9-type TTX-R Na ${ }^{+}$current and Kdr current. By varying relative magnitude of TTX-S and TTX-R Nav currents and recording the model responses to sub- and supra-threshold current injections for AP firing, it was shown that although Nav1.9-type $\mathrm{Na}^{+}$current does not contribute substantially to the inward current during AP upstroke, it provides an important depolarizing influence to resting membrane potential (RMP) and amplifies sub-threshold excitatory inputs.

The hyperpolarization-activated cation current $\left(\mathrm{I}_{\mathrm{h}}, \mathrm{HCN}\right)$ was added to the earlier model (Herzog et al. 2001) and its role in excitability and shaping APs of small DRG neurons was explored (Kouranova et al. 2008). The characteristics of simulated $\mathrm{I}_{\mathrm{h}}$ current (kinetics, steady-state, and conductance parameters) were based on experimental recordings from small DRG neurons, in which $\mathrm{I}_{\mathrm{h}}$ current has significantly smaller density and slower activation kinetics than in large diameter neurons. In the absence of $I_{h}$, the RMP was close to the reversal potential of Kdr. Inclusion of $\mathrm{I}_{\mathrm{h}}$ resulted in a $+16 \mathrm{mV}$-shift of RMP and occurrence of characteristic excitatory rebounds after membrane hyperpolarization. In addition, $\mathrm{I}_{\mathrm{h}}$ was shown to facilitate subthreshold membrane potential oscillations that are known to trigger ectopic discharges in afferent axons and cell somata after nerve trauma (Liu et al. 2000; Amir et al. 2002; Liu et al. 2002; Amir et al. 2005). 
The contribution of Nav1.7 channels on the excitability of small DRG neurons was explored in a more complex model, which also included channels conducting Nav1.8 current, $\mathrm{Kdr}$ and a transient A-type $\mathrm{K}^{+}$(KA) current (Sheets et al. 2007). Such model composition was motivated by the abundant expression of Nav1.7 in nociceptive neurons (Djouhri et al. 2003) and association of a severe phenotype of hereditary erythromelalgia with a particular (N395K) Nav1.7 mutation that lies within the local anaesthetic binding site of the channel (Drenth et al. 2005). The Nav1.7N395K mutant channel differs from WT by a hyperpolarized voltage dependence of activation and impaired (right-shifted) steady-state slow inactivation. The model revealed functional consequences of such difference, when the channels operate in the environment of other channel subtypes: the hyperpolarization shift in activation was found to be the major determinant of hyperexcitability induced by the erythromelalgia mutation, but changes in slow inactivation also contribute to enhanced excitability.

The respective role to the excitability of small DRG neurons of Nav1.7 and Nav1.8, another Nav subunit strongly expressed in nociceptive neurons (Brock et al. 1998; Strassman and Raymond 1999; Black and Waxman 2002; Zimmermann et al. 2007; Persson et al. 2010), was further examined in a similar model (Choi and Waxman 2011). To this aim, the partial conductance of these currents was changed so that one of them (Nav1.7 or Nav1.8) was set on full level and its counterpart varied or eliminated. In the presence of both Nav1.7 and Nav1.8 conductances, the simulated neuron responded to sustained depolarizations by a periodical sequence of spikes with subthreshold membrane potential oscillations of increasing amplitude within interspike intervals. The oscillations disappeared in the absence of Nav1.8 and were magnified by addition of Nav1.7 in a cell containing Nav1.8. Moreover, increasing levels of expression of Nav1.8 resulted in a decrease of Nav1.7 current activated during sustained depolarizations, due to accumulation of 
channels into fast inactivated states. These simulations indicate that the respective level of Nav1.7 and Nav1.8 provides a regulatory mechanism that tunes the excitability of small DRG neurons. The interplay of Nav1.7 and Nav1.8 currents is crucial for the repetitive firing of DRG neurons since Nav1.7 operates in the subthreshold range to amplify small inputs by producing graded depolarizing responses, and Nav1.8 provides the majority of the inward current responsible for the upstroke of APs. The relative magnitude of Nav1.7 and Nav1.8 may change during disease (Luo et al. 2008; Strickland et al. 2008), peripheral nerve injury, limb amputation (Coward et al. 2000; Coward et al. 2001; Kim et al. 2002; Kretschmer et al. 2002; Black et al. 2008), and action of proinflammatory mediators (Black et al. 2004).

The contribution of Nav1.9 current to the hyperexcitability produced by inflammatory mediators was studied in a combined experimental and simulation study with the use of a model containing Nav1.8, Nav1.9, Kdr, and KCNQ (Kv7) channels (Maingret et al. 2008). Nav1.9 channels were shown to contribute to plateau potentials, oscillatory bursting activities and conditional bistable behaviors. The model responded to the 5-ms depolarizing stimulus by generation of a subthreshold regenerative depolarization and AP followed by a plateau potential triggering spike burst as observed experimentally. The model allowed observing all component currents inaccessible in the in vitro experiments and thus revealing the mechanism underlying such response patterns. It was done with the use of a dynamic voltage-clamp protocol employing a special command voltage. The latter was a pre-recorded plateau potential crowned with a burst of APs, which was evoked by a short depolarizing pulse. The partial current traces accompanying this voltage command confirmed that Nav1.9 current does not contribute substantially to the APs during burst but is time-tuned with subthreshold depolarization triggering first AP and subsequent depolarizing plateau phase. Conversely, Nav1.8 was responsible for the surge of $\mathrm{Na}^{+}$ 
current that occurs during the rising phase of APs but had only minor implication in the later phase of the plateau depolarization. This mechanism may sustain nociceptor hyperexcitability during peripheral inflammation since inflammatory mediators were shown to upregulate Nav1.9 current, lowering excitability threshold.

\section{A Model of C-HTMR with slow adapting MS current as mechanical transducers}

Mechanosensory transduction and evoked or spontaneous activity related to normal or pathological pain were out of scope of earlier models of primary nociceptor neurons (see above). We developed a model of C-HTMR that provides a quantitative description of the neurobiological processes that precede or accompany the pain experience, including the transduction, transmission and modulation of cutaneous noxious stimuli (Figure 2). The model included the peripheral and central non-myelinated thin $(0.5 \mu \mathrm{m})$ branches formed by a trunk emerging from the soma homogeneously populated with fast-inactivating TTX-S $\mathrm{Na}^{+}$channels, $\mathrm{Kdr}$, and passive leakage channels. The peripheral axon terminated with a transduction zone (TZ), which contains Nav1.8 and Nav1.9 channels, Kdr, and leak channels as well as slowly adapting MS channels. Biophysical properties of Nav1.8, Nav1.9 and Kdr were derived from earlier models (Maingret et al. 2008). Numerical simulation for slowly adapting MS channels derived from a four-state gating mechanism similar to that described for Piezo1 channels (Lewis et al. 2017) but with slower kinetics (Fig. 2B). Steady IVs characterizing the channels present in our C-HTMR model are shown in Figs 2B (Kdr), 2C (Nav1.8 and Nav1.9) and 2D (Na-TTXs). The effect of inflammation was simulated by a 6 or $20 \mathrm{mV}$-hyperpolarization shift of Nav1.9 activation/inactivation kinetics (Fig. 2C, thick lines). The neuropathic condition associated with a post-lesional accumulation of slowly adapting MS channels was simulated by a $33 \%$ increase in MS channel maximal conductivity. 


\section{Simulated C-HTMR firing patterns related to normal, inflammatory, and neuropathic conditions}

Under normal conditions (Figure 3, left column), application of a trapezoid supra-threshold mechanical stimulus to TZ (A) activated slow adapting MS channels conducting an inward current (B). Noteworthy, the MS current was non-zero before and after the stimulus because the open kinetics state was not empty - at basal plasma membrane tension - in the absence of the mechanical stimulation. This "basal" current contributed to the resting depolarization of TZ relative to the RP of the peripheral axon. However, it was insufficient for activation of spikegenerating $\mathrm{Na}^{+}$currents. When activated, the MS current (B) produced a depolarization that was amplified by activation of Nav1.9 channels (C). This resulted in a large receptor potential (D), which spreads into adjacent peripheral axon and triggers a burst of APs (E) conducted to the central ending $(F)$. Such activity can be considered as a normal pain signal providing a reference for abnormal cases.

Inflammatory conditions \#1 and \#2 (Figure 3, middle columns) each brings the neuron to a sustained pre-stimulus firing with a frequency of 97 and $8 \mathrm{~Hz}$, respectively. This happened because the depolarizing effects of both basal MS current and persistent Nav1.9 current component bring the membrane potential into a supra-threshold range for spiking. Compared to the normal case (left column), the pre-stimulus Nav1.9 current increased about 5.6 and 3.8 times from $-0.6 \mu \mathrm{A} / \mathrm{cm}^{2}$ in control to $-2.3 \mu \mathrm{A} / \mathrm{cm}^{2}$ and $-3.4 \mu \mathrm{A} / \mathrm{cm}^{2}$, respectively (C). During the stimulus, the firing frequency noticeably increased reaching a peak value of 287 and $281 \mathrm{~Hz}$ (E) on the top of the depolarization receptor potential (D), which reached -36.05 and $-36.28 \mathrm{mV}$, respectively. At these potentials, Nav1.9 current with $6 \mathrm{mV}$ negatively shifted IV was activated to $64 \%$ of its peak value $\left(-2.66 \mu \mathrm{A} / \mathrm{cm}^{2}\right.$ at $\left.-42.5 \mathrm{mV}\right)$ whereas that with $20 \mathrm{mV}$ negatively shifted IV 
was nearly inactivated ( $6 \%$ of peak $-3.0966 \mu \mathrm{A} / \mathrm{cm}^{2}$ at $-56.5 \mathrm{mV}$ ) (Fig. 2D). This explains the decrease in Nav1.9 current seen during the receptor potential compared to pre-stimulus basal value in the inflammatory condition \#2 (Fig. 3C). Such ongoing firings can be considered as coding the afferent message of sensitized HTMRs during acute inflammation.

The neuropathic condition (Figure 3, right column) differed from the normal one (left column) by a 33\% increase in slow adapting MS channel conductivity. Both peak and basal MS currents (B) increased to $-310.4 \mu \mathrm{A} / \mathrm{cm}^{2}(+30.5 \%)$ and $-21.9 \mu \mathrm{A} / \mathrm{cm}^{2}(+23.2 \%)$, respectively. Depolarization induced by basal activity of MS currents in (D) was amplified by activation of Nav1.9 channels (C), triggering firing (E, F) with a frequency of $33 \mathrm{~Hz}$. During mechanical stimulation (A) the firing rate increased to peak value of $298 \mathrm{~Hz}(\mathrm{E}, \mathrm{F})$ that was nearly the same as inflammatory conditions. The firing pattern observed in this condition can exemplify signaling of a neuropathic mechanical pain related to post-lesional accumulation of MS channels in peripheral terminals of C-HTMRs.

Computational experiments with our model of C-HTMRs draw attention to the point earlier escaped from consideration and discussion. Conventionally, greater or smaller effects of sensory stimulus were thought in terms of greater or smaller evoked depolarization receptor potentials. This concept still has no direct experimental evidence because thin C-nociceptor fibers and their even thinner sensory endings remain inaccessible for electrophysiological recordings. The computer modeling allows virtual access to these sites. Simulated recordings (Fig. 3) show that not only the receptor potential, but also the basal level of the membrane potential in $\mathrm{TZ}$ and adjacent peripheral axon does matter. The cocktail of channels presumably present in the Cmechanonociceptor sensory ending (Figure 2A) does not provide by its own the generation of APs. It provides a source of the depolarizing current delivered to the electrically coupled pre-TZ 
peripheral axon containing channels specialized in the APs generation and propagation. Noteworthy, existing estimates (Carr et al. 2002) suggest that at rest the sensory terminal ending can be more depolarized than the pre-terminal peripheral axon. The channel cocktail of TZ with those of other parts of our simulated C-HTMR form a system which robustly converts the mechanically evoked phasic receptor potential into a burst of APs. This system is fine-tuned by the basal level of membrane depolarization: sustained firing interpreted as a signal of unprovoked persisting pain occurs if basal depolarization is within a relatively narrow, few $\mathrm{mV}$-width, range. The model demonstrates that Nav1.9 and MS channels with the given kinetic properties under pathological conditions can conduct abnormally increased basal inward currents bringing the membrane depolarization into the range of sustained AP firing.

This set of simulation may help explain the paradoxical relationship between Nav1.9 channel dysfunction and clinical phenotypes. Mutations of Nav1.9 in humans have been associated with either inability to sense pain (Leipold et al. 2013; Woods et al. 2015) or the opposite phenotype of painful peripheral neuropathy (Zhang et al. 2013; Huang et al. 2014; Leipold et al. 2015; Okuda et al. 2016). However studies of mutant Nav1.9 channels all showed hyperpolarizing shifts in channel activation, consistent with a gain of function at the channel level. A recent study (Huang et al. 2017) has solved this apparent conundrum by demonstrating that the L1302F Nav1.9 mutation, which leads to substantially enhanced overlap between activation and steadystate inactivation relationships (e.g. persistent current), reduces the excitability of DRG neurons through inactivation of Nav channels, consistent with impaired pain sensation at the clinical level. This points out to the interplay between the RMP and AP threshold, where small depolarization cause hyperexcitability (painful neuropathy), while larger depolarization causes hypoexcitability (insensitivity to pain). Thus, input-output properties of nociceptors depend on the RMP, the effect 
of transducer depolarization on membrane potential, and on the dynamics/properties of the spike threshold.

\section{Conclusion and future directions}

Despite technical difficulties, enormous progress has been made in recent years in understanding many aspects of mechanosensation. The specialized cell types found in the skin and involved in sensing touch and vibration, as well as the evidence for subsets of sensory DRG neurons that respond to noxious mechanical stimuli is now well established. The MS channel Piezo2 is intimately associated with soft touch and propriception, but the molecular identity of the MS channels transducing noxious mechanical cues remains to be discovered. Although none of the recently tested candidates, including TRP, ASIC and TMEM members unequivocally fulfill the criteria for genuine MS channels, this should not deter speculation regarding their contribution in mechanosensation.

Our knowledge is still far from complete with regard to the full complement and localization of voltage-gated channels and MS sensors in HTMR nerve endings, the coding of the quality of the stimulus and the specific role of each ion channel in pathophysiological pain. Obviously, the clinically relevant question in the field is how mechanical allodynia and hyperalgesia occur, and how they can be blocked. Inflammatory mediators and neuropathic conditions are known to affect mechanical pain thresholds by altering both transduction mechanisms and electrogenesis of nociceptors. Dissecting mechanisms of mechanical sensitization therefore requires an understanding of both general changes of excitability as well as specific effects on mechanotransducer channels. Studies using native somatosensory neurons and their computer 
avatars will thrust the direction of research toward a better understanding of mechanical pain hypersensitivity. 


\section{REFERENCES}

Abraira, V. E. and D. D. Ginty (2013). "The sensory neurons of touch." Neuron 79(4): 618-639.

Alamri, A., R. Bron, J. A. Brock and J. J. Ivanusic (2015). "Transient receptor potential cation channel subfamily $\mathrm{V}$ member 1 expressing corneal sensory neurons can be subdivided into at least three subpopulations." Front Neuroanat 9: 71.

Alessandri-Haber, N., O. A. Dina, E. K. Joseph, D. Reichling and J. D. Levine (2006). "A transient receptor potential vanilloid 4-dependent mechanism of hyperalgesia is engaged by concerted action of inflammatory mediators." J Neurosci 26(14): 3864-3874.

Alloui, A., K. Zimmermann, J. Mamet, F. Duprat, J. Noel, J. Chemin, N. Guy, N. Blondeau, N. Voilley, C. Rubat-Coudert, M. Borsotto, G. Romey, C. Heurteaux, P. Reeh, A. Eschalier and M. Lazdunski (2006). "TREK-1, a K+ channel involved in polymodal pain perception." Embo J 25(11): 23682376.

Amir, R., J. D. Kocsis and M. Devor (2005). "Multiple interacting sites of ectopic spike electrogenesis in primary sensory neurons." J Neurosci 25(10): 2576-2585.

Amir, R., M. Michaelis and M. Devor (2002). "Burst discharge in primary sensory neurons: triggered by subthreshold oscillations, maintained by depolarizing afterpotentials." J Neurosci 22(3): 11871198.

Basbaum, A. I., D. M. Bautista, G. Scherrer and D. Julius (2009). "Cellular and molecular mechanisms of pain." Cell 139(2): 267-284.

Bautista, D. M., S. E. Jordt, T. Nikai, P. R. Tsuruda, A. J. Read, J. Poblete, E. N. Yamoah, A. I. Basbaum and D. Julius (2006). "TRPA1 mediates the inflammatory actions of environmental irritants and proalgesic agents." Cell 124(6): 1269-1282.

Black, J. A., S. Liu, M. Tanaka, T. R. Cummins and S. G. Waxman (2004). "Changes in the expression of tetrodotoxin-sensitive sodium channels within dorsal root ganglia neurons in inflammatory pain." Pain 108(3): 237-247.

Black, J. A., L. Nikolajsen, K. Kroner, T. S. Jensen and S. G. Waxman (2008). "Multiple sodium channel isoforms and mitogen-activated protein kinases are present in painful human neuromas." Ann Neurol 64(6): 644-653.

Black, J. A. and S. G. Waxman (2002). "Molecular identities of two tetrodotoxin-resistant sodium channels in corneal axons." Exp Eye Res 75(2): 193-199.

Bourinet, E., A. Alloui, A. Monteil, C. Barrere, B. Couette, O. Poirot, A. Pages, J. McRory, T. P. Snutch, A. Eschalier and J. Nargeot (2005). "Silencing of the Cav3.2 T-type calcium channel gene in sensory neurons demonstrates its major role in nociception." EMBO J 24(2): 315-324.

Brierley, S. M., J. Castro, A. M. Harrington, P. A. Hughes, A. J. Page, G. Y. Rychkov and L. A. Blackshaw (2011). "TRPA1 contributes to specific mechanically activated currents and sensory neuron mechanical hypersensitivity." J Physiol 589(Pt 14): 3575-3593.

Brock, J. A., E. M. McLachlan and C. Belmonte (1998). "Tetrodotoxin-resistant impulses in single nociceptor nerve terminals in guinea-pig cornea." J Physiol 512 ( Pt 1): 211-217.

Brohawn, S. G., Z. Su and R. MacKinnon (2014). "Mechanosensitivity is mediated directly by the lipid membrane in TRAAK and TREK1 K+ channels." Proc Natl Acad Sci U S A 111(9): 3614-3619.

Bron, R., R. J. Wood, J. A. Brock and J. J. Ivanusic (2014). "Piezo2 expression in corneal afferent neurons." J Comp Neurol 522(13): 2967-2979.

Brown, A. G. and A. Iggo (1967). "A quantitative study of cutaneous receptors and afferent fibres in the cat and rabbit." J Physiol 193(3): 707-733.

Carr, R. W., S. Pianova and J. A. Brock (2002). "The effects of polarizing current on nerve terminal impulses recorded from polymodal and cold receptors in the guinea-pig cornea." J Gen Physiol 120(3): 395-405. 
Choi, J. S. and S. G. Waxman (2011). "Physiological interactions between $\mathrm{Na(v)1.7} \mathrm{and} \mathrm{Na(v)1.8} \mathrm{sodium}$ channels: a computer simulation study." J Neurophysiol 106(6): 3173-3184.

Christensen, A. P. and D. P. Corey (2007). "TRP channels in mechanosensation: direct or indirect activation?" Nat Rev Neurosci 8(7): 510-521.

Coetzee, W. A., Y. Amarillo, J. Chiu, A. Chow, D. Lau, T. McCormack, H. Moreno, M. S. Nadal, A. Ozaita, D. Pountney, M. Saganich, E. Vega-Saenz de Miera and B. Rudy (1999). "Molecular diversity of K+ channels." Ann N Y Acad Sci 868: 233-285.

Copel, C., N. Clerc, N. Osorio, P. Delmas and B. Mazet (2013). "The Nav1.9 channel regulates colonic motility in mice." Front Neurosci 7: 58.

Coste, B., M. Crest and P. Delmas (2007). "Pharmacological Dissection and Distribution of NaN/Nav1.9, T-type Ca2+ Currents, and Mechanically Activated Cation Currents in Different Populations of DRG Neurons." J Gen Physiol 129(1): 57-77.

Coste, B., J. Mathur, M. Schmidt, T. J. Earley, S. Ranade, M. J. Petrus, A. E. Dubin and A. Patapoutian (2010). "Piezo1 and Piezo2 are essential components of distinct mechanically activated cation channels." Science 330(6000): 55-60.

Coste, B., N. Osorio, F. Padilla, M. Crest and P. Delmas (2004). "Gating and modulation of presumptive NaV1.9 channels in enteric and spinal sensory neurons." Mol Cell Neurosci 26(1): 123-134.

Coste, B., B. Xiao, J. S. Santos, R. Syeda, J. Grandl, K. S. Spencer, S. E. Kim, M. Schmidt, J. Mathur, A. E. Dubin, M. Montal and A. Patapoutian (2012). "Piezo proteins are pore-forming subunits of mechanically activated channels." Nature 483(7388): 176-181.

Coward, K., A. Aitken, A. Powell, C. Plumpton, R. Birch, S. Tate, C. Bountra and P. Anand (2001). "Plasticity of TTX-sensitive sodium channels PN1 and brain III in injured human nerves." Neuroreport 12(3): 495-500.

Coward, K., C. Plumpton, P. Facer, R. Birch, T. Carlstedt, S. Tate, C. Bountra and P. Anand (2000). "Immunolocalization of SNS/PN3 and NaN/SNS2 sodium channels in human pain states." Pain 85(1-2): 41-50.

Cummins, T. R., S. D. Dib-Hajj, J. A. Black, A. N. Akopian, J. N. Wood and S. G. Waxman (1999). "A novel persistent tetrodotoxin-resistant sodium current in SNS-null and wild-type small primary sensory neurons." J Neurosci 19(24): RC43.

Delfini, M. C., A. Mantilleri, S. Gaillard, J. Hao, A. Reynders, P. Malapert, S. Alonso, A. Francois, C. Barrere, R. Seal, M. Landry, A. Eschallier, A. Alloui, E. Bourinet, P. Delmas, Y. Le Feuvre and A. Moqrich (2013). "TAFA4, a chemokine-like protein, modulates injury-induced mechanical and chemical pain hypersensitivity in mice." Cell Rep 5(2): 378-388.

Delmas, P. and D. A. Brown (2005). "Pathways modulating neural KCNQ/M (Kv7) potassium channels." Nat Rev Neurosci 6(11): 850-862.

Delmas, P. and B. Coste (2013). "Mechano-gated ion channels in sensory systems." Cell 155(2): 278284.

Delmas, P., J. Hao and L. Rodat-Despoix (2011). "Molecular mechanisms of mechanotransduction in mammalian sensory neurons." Nat Rev Neurosci 12(3): 139-153.

Djouhri, L. and S. N. Lawson (2004). "Abeta-fiber nociceptive primary afferent neurons: a review of incidence and properties in relation to other afferent A-fiber neurons in mammals." Brain Res Brain Res Rev 46(2): 131-145.

Djouhri, L., R. Newton, S. R. Levinson, C. M. Berry, B. Carruthers and S. N. Lawson (2003). "Sensory and electrophysiological properties of guinea-pig sensory neurones expressing Nav 1.7 (PN1) Na+ channel alpha subunit protein." J Physiol 546(Pt 2): 565-576.

Drenth, J. P., R. H. te Morsche, G. Guillet, A. Taieb, R. L. Kirby and J. B. Jansen (2005). "SCN9A mutations define primary erythermalgia as a neuropathic disorder of voltage gated sodium channels." J Invest Dermatol 124(6): 1333-1338. 
Drew, L. J., D. K. Rohrer, M. P. Price, K. E. Blaver, D. A. Cockayne, P. Cesare and J. N. Wood (2004). "Acid-sensing ion channels ASIC2 and ASIC3 do not contribute to mechanically activated currents in mammalian sensory neurones." J Physiol 556(Pt 3): 691-710.

Drew, L. J., F. Rugiero, P. Cesare, J. E. Gale, B. Abrahamsen, S. Bowden, S. Heinzmann, M. Robinson, A. Brust, B. Colless, R. J. Lewis and J. N. Wood (2007). "High-threshold mechanosensitive ion channels blocked by a novel conopeptide mediate pressure-evoked pain." PLOS ONE 2: e515.

Drew, L. J. and J. N. Wood (2007). "FM1-43 is a permeant blocker of mechanosensitive ion channels in sensory neurons and inhibits behavioural responses to mechanical stimuli." Mol Pain 3: 1.

Drew, L. J., J. N. Wood and P. Cesare (2002). "Distinct mechanosensitive properties of capsaicinsensitive and -insensitive sensory neurons." J Neurosci 22(12): RC228.

Du, X., H. Gao, D. Jaffe, H. Zhang and N. Gamper (2017). "M-type K(+) channels in peripheral nociceptive pathways." Br J Pharmacol.

Dubin, A. E., S. Murthy, A. H. Lewis, L. Brosse, S. M. Cahalan, J. Grandl, B. Coste and A. Patapoutian (2017). "Endogenous Piezo1 Can Confound Mechanically Activated Channel Identification and Characterization." Neuron 94(2): 266-270 e263.

Dubin, A. E. and A. Patapoutian (2010). "Nociceptors: the sensors of the pain pathway." J Clin Invest 120(11): 3760-3772.

Dubin, A. E., M. Schmidt, J. Mathur, M. J. Petrus, B. Xiao, B. Coste and A. Patapoutian (2012). "Inflammatory signals enhance piezo2-mediated mechanosensitive currents." Cell Rep 2(3): 511-517.

Dubreuil, A. S., H. Boukhaddaoui, G. Desmadryl, C. Martinez-Salgado, R. Moshourab, G. R. Lewin, P. Carroll, J. Valmier and F. Scamps (2004). "Role of T-type calcium current in identified D-hair mechanoreceptor neurons studied in vitro." J Neurosci 24(39): 8480-8484.

Eijkelkamp, N., J. E. Linley, J. M. Torres, L. Bee, A. H. Dickenson, M. Gringhuis, M. S. Minett, G. S. Hong, E. Lee, U. Oh, Y. Ishikawa, F. J. Zwartkuis, J. J. Cox and J. N. Wood (2013). "A role for Piezo2 in EPAC1-dependent mechanical allodynia." Nat Commun 4: 1682.

Eitner, A., G. O. Hofmann and H. G. Schaible (2017). "Mechanisms of Osteoarthritic Pain. Studies in Humans and Experimental Models." Front Mol Neurosci 10: 349.

Fleming, M. S. and W. Luo (2013). "The anatomy, function, and development of mammalian Abeta low-threshold mechanoreceptors." Front Biol (Beijing) 8(4).

Florez-Paz, D., K. K. Bali, R. Kuner and A. Gomis (2016). "A critical role for Piezo2 channels in the mechanotransduction of mouse proprioceptive neurons." Sci Rep 6: 25923.

Francois, A., S. Laffray, A. Pizzoccaro, A. Eschalier and E. Bourinet (2014). "T-type calcium channels in chronic pain: mouse models and specific blockers." Pflugers Arch 466(4): 707-717.

Francois, A., N. Schuetter, S. Laffray, J. Sanguesa, A. Pizzoccaro, S. Dubel, A. Mantilleri, J. Nargeot, J. Noel, J. N. Wood, A. Moqrich, O. Pongs and E. Bourinet (2015). "The Low-Threshold Calcium Channel Cav3.2 Determines Low-Threshold Mechanoreceptor Function." Cell Rep.

Garcia-Anoveros, J., T. A. Samad, L. Zuvela-Jelaska, C. J. Woolf and D. P. Corey (2001). "Transport and localization of the $\mathrm{DEG} / \mathrm{ENaC}$ ion channel $\mathrm{BNaC1}$ alpha to peripheral mechanosensory terminals of dorsal root ganglia neurons." J Neurosci 21(8): 2678-2686.

Gebhart, G. F. and K. Bielefeldt (2016). "Physiology of Visceral Pain." Compr Physiol 6(4): 1609-1633.

Goldstein, S. A., D. A. Bayliss, D. Kim, F. Lesage, L. D. Plant and S. Rajan (2005). "International Union of Pharmacology. LV. Nomenclature and molecular relationships of two-P potassium channels." Pharmacol Rev 57(4): 527-540.

Guo, Y. R. and R. MacKinnon (2017). "Structure-based membrane dome mechanism for Piezo mechanosensitivity." Elife 6.

Hao, J. and P. Delmas (2010). "Multiple desensitization mechanisms of mechanotransducer channels shape firing of mechanosensory neurons." J Neurosci 30(40): 13384-13395. 
Hao, J. and P. Delmas (2011). "Recording of mechanosensitive currents using piezoelectrically driven mechanostimulator." Nat Protoc 6(7): 979-990.

Hao, J., F. Padilla, M. Dandonneau, C. Lavebratt, F. Lesage, J. Noel and P. Delmas (2013). "Kv1.1 channels act as mechanical brake in the senses of touch and pain." Neuron 77(5): 899-914.

Heidenreich, M., S. G. Lechner, V. Vardanyan, C. Wetzel, C. W. Cremers, E. M. De Leenheer, G. Aranguez, M. A. Moreno-Pelayo, T. J. Jentsch and G. R. Lewin (2011). "KCNQ4 K(+) channels tune mechanoreceptors for normal touch sensation in mouse and man." Nat Neurosci 15(1): 138-145.

Herzog, R. I., T. R. Cummins and S. G. Waxman (2001). "Persistent TTX-resistant Na+ current affects resting potential and response to depolarization in simulated spinal sensory neurons." J Neurophysiol 86(3): 1351-1364.

Hilaire, C., O. Lucas, J. Valmier and F. Scamps (2012). "Neurotrophin-4 modulates the mechanotransducer Cav3.2 T-type calcium current in mice down-hair neurons." Biochem J 441(1): 463-471.

Hockley, J. R., G. Boundouki, V. Cibert-Goton, C. McGuire, P. K. Yip, C. Chan, M. Tranter, J. N. Wood, M. A. Nassar, L. A. Blackshaw, Q. Aziz, G. J. Michael, M. D. Baker, W. J. Winchester, C. H. Knowles and D. C. Bulmer (2014). "Multiple roles for NaV1.9 in the activation of visceral afferents by noxious inflammatory, mechanical, and human disease-derived stimuli." Pain 155(10): 19621975.

Hoffmann, T., K. Kistner, R. W. Carr, M. A. Nassar, P. W. Reeh and C. Weidner (2017). "Reduced excitability and impaired nociception in peripheral unmyelinated fibers from Nav1.9-null mice." Pain 158(1): 58-67.

Hong, G. S., B. Lee, J. Wee, H. Chun, H. Kim, J. Jung, J. Y. Cha, T. R. Riew, G. H. Kim, I. B. Kim and U. Oh (2016). "Tentonin 3/TMEM150c Confers Distinct Mechanosensitive Currents in Dorsal-Root Ganglion Neurons with Proprioceptive Function." Neuron 91(3): 708-710.

Honore, E. (2007). "The neuronal background K2P channels: focus on TREK1." Nat Rev Neurosci 8(4): 251-261.

Hu, J. and G. R. Lewin (2006). "Mechanosensitive currents in the neurites of cultured mouse sensory neurones." J Physiol 577(Pt 3): 815-828.

Huang, J., C. Han, M. Estacion, D. Vasylyev, J. G. Hoeijmakers, M. M. Gerrits, L. Tyrrell, G. Lauria, C. G. Faber, S. D. Dib-Hajj, I. S. Merkies and S. G. Waxman (2014). "Gain-of-function mutations in sodium channel $\mathrm{Na}(v) 1.9$ in painful neuropathy." Brain 137(Pt 6): 1627-1642.

Huang, J., C. G. Vanoye, A. Cutts, Y. P. Goldberg, S. D. Dib-Hajj, C. J. Cohen, S. G. Waxman and A. L. George, Jr. (2017). "Sodium channel NaV1.9 mutations associated with insensitivity to pain dampen neuronal excitability." J Clin Invest 127(7): 2805-2814.

Kang, D. and D. Kim (2006). "TREK-2 (K2P10.1) and TRESK (K2P18.1) are major background K+ channels in dorsal root ganglion neurons." Am J Physiol Cell Physiol 291(1): C138-146.

Kerstein, P. C., D. del Camino, M. M. Moran and C. L. Stucky (2009). "Pharmacological blockade of TRPA1 inhibits mechanical firing in nociceptors." Mol Pain 5: 19.

Kim, C. H., Y. Oh, J. M. Chung and K. Chung (2002). "Changes in three subtypes of tetrodotoxin sensitive sodium channel expression in the axotomized dorsal root ganglion in the rat." Neurosci Lett 323(2): 125-128.

Kouranova, E. V., B. W. Strassle, R. H. Ring, M. R. Bowlby and D. V. Vasilyev (2008). "Hyperpolarizationactivated cyclic nucleotide-gated channel mRNA and protein expression in large versus small diameter dorsal root ganglion neurons: correlation with hyperpolarization-activated current gating." Neuroscience 153(4): 1008-1019. 
Kretschmer, T., L. T. Happel, J. D. England, D. H. Nguyen, R. L. Tiel, R. W. Beuerman and D. G. Kline (2002). "Accumulation of PN1 and PN3 sodium channels in painful human neuroma-evidence from immunocytochemistry." Acta Neurochir (Wien) 144(8): 803-810; discussion 810.

Kubisch, C., B. C. Schroeder, T. Friedrich, B. Lutjohann, A. El-Amraoui, S. Marlin, C. Petit and T. J. Jentsch (1999). "KCNQ4, a novel potassium channel expressed in sensory outer hair cells, is mutated in dominant deafness." Cell 96(3): 437-446.

Kumazawa, T. (1996). "The polymodal receptor: bio-warning and defense system." Prog Brain Res 113: 3-18.

Kwan, K. Y., A. J. Allchorne, M. A. Vollrath, A. P. Christensen, D. S. Zhang, C. J. Woolf and D. P. Corey (2006). "TRPA1 contributes to cold, mechanical, and chemical nociception but is not essential for hair-cell transduction." Neuron 50(2): 277-289.

Lechner, S. G. and G. R. Lewin (2009). "Peripheral sensitisation of nociceptors via G-protein-dependent potentiation of mechanotransduction currents." J Physiol 587(Pt 14): 3493-3503.

Lee, S. (2013). "Pharmacological Inhibition of Voltage-gated $\mathrm{Ca}(2+)$ Channels for Chronic Pain Relief." Curr Neuropharmacol 11(6): 606-620.

Leipold, E., A. Hanson-Kahn, M. Frick, P. Gong, J. A. Bernstein, M. Voigt, I. Katona, R. Oliver Goral, J. Altmuller, P. Nurnberg, J. Weis, C. A. Hubner, S. H. Heinemann and I. Kurth (2015). "Coldaggravated pain in humans caused by a hyperactive NaV1.9 channel mutant." Nat Commun 6: 10049.

Leipold, E., L. Liebmann, G. C. Korenke, T. Heinrich, S. Giesselmann, J. Baets, M. Ebbinghaus, R. O. Goral, T. Stodberg, J. C. Hennings, M. Bergmann, J. Altmuller, H. Thiele, A. Wetzel, P. Nurnberg, V. Timmerman, P. De Jonghe, R. Blum, H. G. Schaible, J. Weis, S. H. Heinemann, C. A. Hubner and I. Kurth (2013). "A de novo gain-of-function mutation in SCN11A causes loss of pain perception." Nat Genet 45(11): 1399-1404.

Lennertz, R. C., E. A. Kossyreva, A. K. Smith and C. L. Stucky (2012). "TRPA1 mediates mechanical sensitization in nociceptors during inflammation." PLoS One 7(8): e43597.

Lewin, G. R. and R. Moshourab (2004). "Mechanosensation and pain." J Neurobiol 61(1): 30-44.

Lewis, A. H., A. F. Cui, M. F. McDonald and J. Grandl (2017). "Transduction of Repetitive Mechanical Stimuli by Piezo1 and Piezo2 Ion Channels." Cell Rep 19(12): 2572-2585.

Li, L., M. Rutlin, V. E. Abraira, C. Cassidy, L. Kus, S. Gong, M. P. Jankowski, W. Luo, N. Heintz, H. R. Koerber, C. J. Woodbury and D. D. Ginty (2011). "The functional organization of cutaneous lowthreshold mechanosensory neurons." Cell 147(7): 1615-1627.

Liedtke, W. (2005). "TRPV4 plays an evolutionary conserved role in the transduction of osmotic and mechanical stimuli in live animals." J Physiol 567(Pt 1): 53-58.

Liedtke, W., Y. Choe, M. A. Marti-Renom, A. M. Bell, C. S. Denis, A. Sali, A. J. Hudspeth, J. M. Friedman and S. Heller (2000). "Vanilloid receptor-related osmotically activated channel (VR-OAC), a candidate vertebrate osmoreceptor." Cell 103(3): 525-535.

Lingueglia, E. (2007). "Acid-sensing ion channels in sensory perception." J Biol Chem 282(24): 1732517329.

Liu, C. N., M. Devor, S. G. Waxman and J. D. Kocsis (2002). "Subthreshold oscillations induced by spinal nerve injury in dissociated muscle and cutaneous afferents of mouse DRG." J Neurophysiol 87(4): 2009-2017.

Liu, C. N., M. Michaelis, R. Amir and M. Devor (2000). "Spinal nerve injury enhances subthreshold membrane potential oscillations in DRG neurons: relation to neuropathic pain." J Neurophysiol 84(1): 205-215.

Lolignier, S., M. Amsalem, F. Maingret, F. Padilla, M. Gabriac, E. Chapuy, A. Eschalier, P. Delmas and J. Busserolles (2011). "Nav1.9 channel contributes to mechanical and heat pain hypersensitivity induced by subacute and chronic inflammation." PLoS One 6(8): e23083. 
Lolignier, S., N. Eijkelkamp and J. N. Wood (2015). "Mechanical allodynia." Pflugers Arch 467(1): 133139.

Lou, S., B. Duan, L. Vong, B. B. Lowell and Q. Ma (2013). "Runx1 controls terminal morphology and mechanosensitivity of VGLUT3-expressing C-mechanoreceptors." J Neurosci 33(3): 870-882.

Lu, Y., X. Ma, R. Sabharwal, V. Snitsarev, D. Morgan, K. Rahmouni, H. A. Drummond, C. A. Whiteis, V. Costa, M. Price, C. Benson, M. J. Welsh, M. W. Chapleau and F. M. Abboud (2009). "The ion channel ASIC2 is required for baroreceptor and autonomic control of the circulation." Neuron 64(6): 885-897.

Lumpkin, E. A. and M. J. Caterina (2007). "Mechanisms of sensory transduction in the skin." Nature 445(7130): 858-865.

Luo, S., G. M. Perry, S. R. Levinson and M. A. Henry (2008). "Nav1.7 expression is increased in painful human dental pulp." Mol Pain 4: 16.

Maingret, F., B. Coste, F. Padilla, N. Clerc, M. Crest, S. M. Korogod and P. Delmas (2008).

"Inflammatory mediators increase Nav1.9 current and excitability in nociceptors through a coincident detection mechanism." J Gen Physiol 131(3): 211-225.

Maingret, F., M. Fosset, F. Lesage, M. Lazdunski and E. Honore (1999). "TRAAK is a mammalian neuronal mechano-gated K+ channel." J Biol Chem 274(3): 1381-1387.

Maingret, F., A. J. Patel, F. Lesage, M. Lazdunski and E. Honore (1999). "Mechano- or acid stimulation, two interactive modes of activation of the TREK-1 potassium channel." J Biol Chem 274(38): 26691-26696.

McCarter, G. C. and J. D. Levine (2006). "Ionic basis of a mechanotransduction current in adult rat dorsal root ganglion neurons." Mol Pain 2: 28.

McCarter, G. C., D. B. Reichling and J. D. Levine (1999). "Mechanical transduction by rat dorsal root ganglion neurons in vitro." Neurosci Lett 273(3): 179-182.

Medhurst, A. D., G. Rennie, C. G. Chapman, H. Meadows, M. D. Duckworth, R. E. Kelsell, Gloger, II and M. N. Pangalos (2001). "Distribution analysis of human two pore domain potassium channels in tissues of the central nervous system and periphery." Brain Res Mol Brain Res 86(1-2): 101114.

Meyer, R. A., K. D. Davis, R. H. Cohen, R. D. Treede and J. N. Campbell (1991). "Mechanically insensitive afferents (MIAs) in cutaneous nerves of monkey." Brain Res 561(2): 252-261.

Mienville, J. M. and J. R. Clay (1996). "Effects of intracellular K+ and Rb+ on gating of embryonic rat telencephalon $\mathrm{Ca}(2+)$-activated $\mathrm{K}+$ channels." Biophys J 70(2): 778-785.

Mogil, J. S., N. M. Breese, M. F. Witty, J. Ritchie, M. L. Rainville, A. Ase, N. Abbadi, C. L. Stucky and P. Seguela (2005). "Transgenic expression of a dominant-negative ASIC3 subunit leads to increased sensitivity to mechanical and inflammatory stimuli." J Neurosci 25(43): 9893-9901.

Morris, C. E. (2011). "Voltage-gated channel mechanosensitivity: fact or friction?" Front Physiol 2: 25.

Morris, C. E. and P. F. Juranka (2007). "Nav channel mechanosensitivity: activation and inactivation accelerate reversibly with stretch." Biophys J 93(3): 822-833.

Nencini, S. and J. Ivanusic (2017). "Mechanically sensitive Adelta nociceptors that innervate bone marrow respond to changes in intra-osseous pressure." J Physiol 595(13): 4399-4415.

Noel, J., K. Zimmermann, J. Busserolles, E. Deval, A. Alloui, S. Diochot, N. Guy, M. Borsotto, P. Reeh, A. Eschalier and M. Lazdunski (2009). "The mechano-activated K+ channels TRAAK and TREK-1 control both warm and cold perception." EMBO J 28(9): 1308-1318.

Okuda, H., A. Noguchi, H. Kobayashi, D. Kondo, K. H. Harada, S. Youssefian, H. Shioi, R. Kabata, Y. Domon, K. Kubota, Y. Kitano, Y. Takayama, T. Hitomi, K. Ohno, Y. Saito, T. Asano, M. Tominaga, T. Takahashi and A. Koizumi (2016). "Infantile Pain Episodes Associated with Novel Nav1.9 Mutations in Familial Episodic Pain Syndrome in Japanese Families." PLoS One 11(5): e0154827. 
Omerbasic, D., L. N. Schuhmacher, Y. A. Bernal Sierra, E. S. Smith and G. R. Lewin (2015). "ASICs and mammalian mechanoreceptor function." Neuropharmacology 94: 80-86.

Padilla, F., M.-L. Couble, B. Coste, F. Maingret, N. Clerc, M. Crest, A. M. Ritter, H. Magloire and P. Delmas (2007). "Expression and localization of the Nav1.9 sodium channel in enteric neurons and in trigeminal sensory endings: Implication for intestinal reflex function and orofacial pain." Molecular and Cellular Neuroscience 35(1): 138-152.

Page, A. J., S. M. Brierley, C. M. Martin, C. Martinez-Salgado, J. A. Wemmie, T. J. Brennan, E. Symonds, T. Omari, G. R. Lewin, M. J. Welsh and L. A. Blackshaw (2004). "The ion channel ASIC1 contributes to visceral but not cutaneous mechanoreceptor function." Gastroenterology 127(6): 1739-1747.

Parpaite, T. and B. Coste (2017). "Piezo channels." Curr Biol 27(7): R250-R252.

Passmore, G. M., A. A. Selyanko, M. Mistry, M. Al-Qatari, S. J. Marsh, E. A. Matthews, A. H. Dickenson, T. A. Brown, S. A. Burbidge, M. Main and D. A. Brown (2003). "KCNQ/M currents in sensory neurons: significance for pain therapy." J Neurosci 23(18): 7227-7236.

Patel, A. J., E. Honore, F. Maingret, F. Lesage, M. Fink, F. Duprat and M. Lazdunski (1998). "A mammalian two pore domain mechano-gated S-like K+ channel." EMBO J 17(15): 4283-4290.

Peier, A. M., A. Moqrich, A. C. Hergarden, A. J. Reeve, D. A. Andersson, G. M. Story, T. J. Earley, I. Dragoni, P. Mclntyre, S. Bevan and A. Patapoutian (2002). "A TRP channel that senses cold stimuli and menthol." Cell 108(5): 705-715.

Persson, A. K., J. A. Black, A. Gasser, X. Cheng, T. Z. Fischer and S. G. Waxman (2010). "Sodium-calcium exchanger and multiple sodium channel isoforms in intra-epidermal nerve terminals." Mol Pain 6: 84.

Petersson, M. E., O. Obreja, A. Lampert, R. W. Carr, M. Schmelz and E. Fransen (2014). "Differential axonal conduction patterns of mechano-sensitive and mechano-insensitive nociceptors--a combined experimental and modelling study." PLoS One 9(8): e103556.

Petrus, M., A. M. Peier, M. Bandell, S. W. Hwang, T. Huynh, N. Olney, T. Jegla and A. Patapoutian (2007). "A role of TRPA1 in mechanical hyperalgesia is revealed by pharmacological inhibition." Mol Pain 3(1): 40.

Poole, K., R. Herget, L. Lapatsina, H. D. Ngo and G. R. Lewin (2014). "Tuning Piezo ion channels to detect molecular-scale movements relevant for fine touch." Nat Commun 5: 3520.

Prato, V., F. J. Taberner, J. R. F. Hockley, G. Callejo, A. Arcourt, B. Tazir, L. Hammer, P. Schad, P. A. Heppenstall, E. S. Smith and S. G. Lechner (2017). "Functional and Molecular Characterization of Mechanoinsensitive "Silent" Nociceptors." Cell Rep 21(11): 3102-3115.

Price, M. P., G. R. Lewin, S. L. Mcllwrath, C. Cheng, J. Xie, P. A. Heppenstall, C. L. Stucky, A. G. Mannsfeldt, T. J. Brennan, H. A. Drummond, J. Qiao, C. J. Benson, D. E. Tarr, R. F. Hrstka, B. Yang, R. A. Williamson and M. J. Welsh (2000). "The mammalian sodium channel BNC1 is required for normal touch sensation." Nature 407(6807): 1007-1011.

Price, M. P., S. L. Mcllwrath, J. Xie, C. Cheng, J. Qiao, D. E. Tarr, K. A. Sluka, T. J. Brennan, G. R. Lewin and M. J. Welsh (2001). "The DRASIC cation channel contributes to the detection of cutaneous touch and acid stimuli in mice." Neuron 32(6): 1071-1083.

Ranade, S. S., R. Syeda and A. Patapoutian (2015). "Mechanically Activated Ion Channels." Neuron 87(6): 1162-1179.

Ranade, S. S., S. H. Woo, A. E. Dubin, R. A. Moshourab, C. Wetzel, M. Petrus, J. Mathur, V. Begay, B. Coste, J. Mainquist, A. J. Wilson, A. G. Francisco, K. Reddy, Z. Qiu, J. N. Wood, G. R. Lewin and A. Patapoutian (2014). "Piezo2 is the major transducer of mechanical forces for touch sensation in mice." Nature 516(7529): 121-125.

Ritter, A. M., W. J. Martin and K. S. Thorneloe (2009). "The voltage-gated sodium channel Nav1.9 is required for inflammation-based urinary bladder dysfunction." Neurosci Lett 452(1): 28-32. 
Roudaut, Y., A. Lonigro, B. Coste, J. Hao, P. Delmas and M. Crest (2012). "Touch sense: functional organization and molecular determinants of mechanosensitive receptors." Channels (Austin) 6(4): 234-245.

Roza, C., J. L. Puel, M. Kress, A. Baron, S. Diochot, M. Lazdunski and R. Waldmann (2004). "Knockout of the ASIC2 channel in mice does not impair cutaneous mechanosensation, visceral mechanonociception and hearing." J Physiol 558(Pt 2): 659-669.

Rugiero, F., L. J. Drew and J. N. Wood (2010). "Kinetic properties of mechanically activated currents in spinal sensory neurons." J Physiol 588(Pt 2): 301-314.

Rugiero, F. and J. N. Wood (2009). "The mechanosensitive cell line ND-C does not express functional thermoTRP channels." Neuropharmacology 56(8): 1138-1146.

Rush, A. M. and S. G. Waxman (2004). "PGE2 increases the tetrodotoxin-resistant Nav1.9 sodium current in mouse DRG neurons via G-proteins." Brain Res 1023(2): 264-271.

Saotome, K., S. E. Murthy, J. M. Kefauver, T. Whitwam, A. Patapoutian and A. B. Ward (2017). "Structure of the mechanically activated ion channel Piezo1." Nature.

Schmidt, D., J. del Marmol and R. MacKinnon (2012). "Mechanistic basis for low threshold mechanosensitivity in voltage-dependent K+ channels." Proc Natl Acad Sci U S A 109(26): 10352-10357.

Scriven, D. R. (1981). "Modeling repetitive firing and bursting in a small unmyelinated nerve fiber." Biophys J 35(3): 715-730.

Sheets, P. L., J. O. Jackson, 2nd, S. G. Waxman, S. D. Dib-Hajj and T. R. Cummins (2007). "A Nav1.7 channel mutation associated with hereditary erythromelalgia contributes to neuronal hyperexcitability and displays reduced lidocaine sensitivity." J Physiol 581(Pt 3): 1019-1031.

Story, G. M., A. M. Peier, A. J. Reeve, S. R. Eid, J. Mosbacher, T. R. Hricik, T. J. Earley, A. C. Hergarden, D. A. Andersson, S. W. Hwang, P. Mclntyre, T. Jegla, S. Bevan and A. Patapoutian (2003). "ANKTM1, a TRP-like channel expressed in nociceptive neurons, is activated by cold temperatures." Cell 112(6): 819-829.

Strassman, A. M. and S. A. Raymond (1999). "Electrophysiological evidence for tetrodotoxin-resistant sodium channels in slowly conducting dural sensory fibers." J Neurophysiol 81(2): 413-424.

Strickland, I. T., J. C. Martindale, P. L. Woodhams, A. J. Reeve, I. P. Chessell and D. S. McQueen (2008). "Changes in the expression of NaV1.7, NaV1.8 and NaV1.9 in a distinct population of dorsal root ganglia innervating the rat knee joint in a model of chronic inflammatory joint pain." Eur $J$ Pain 12(5): 564-572.

Sundt, D., N. Gamper and D. B. Jaffe (2015). "Spike propagation through the dorsal root ganglia in an unmyelinated sensory neuron: a modeling study." J Neurophysiol 114(6): 3140-3153.

Suzuki, M., A. Mizuno, K. Kodaira and M. Imai (2003). "Impaired pressure sensation in mice lacking TRPV4." J Biol Chem 278(25): 22664-22668.

Swayne, L. A. and E. Bourinet (2008). "Voltage-gated calcium channels in chronic pain: emerging role of alternative splicing." Pflugers Arch 456(3): 459-466.

Syeda, R., M. N. Florendo, C. D. Cox, J. M. Kefauver, J. S. Santos, B. Martinac and A. Patapoutian (2016). "Piezo1 Channels Are Inherently Mechanosensitive." Cell Rep 17(7): 1739-1746.

Tigerholm, J., M. E. Petersson, O. Obreja, A. Lampert, R. Carr, M. Schmelz and E. Fransen (2014). "Modeling activity-dependent changes of axonal spike conduction in primary afferent Cnociceptors." J Neurophysiol 111(9): 1721-1735.

Tominaga, M., M. J. Caterina, A. B. Malmberg, T. A. Rosen, H. Gilbert, K. Skinner, B. E. Raumann, A. I. Basbaum and D. Julius (1998). "The cloned capsaicin receptor integrates multiple painproducing stimuli." Neuron 21(3): 531-543.

Vanoye, C. G., J. D. Kunic, G. R. Ehring and A. L. George, Jr. (2013). "Mechanism of sodium channel NaV1.9 potentiation by G-protein signaling." J Gen Physiol 141(2): 193-202. 
Vilceanu, D. and C. L. Stucky (2010). "TRPA1 mediates mechanical currents in the plasma membrane of mouse sensory neurons." PLoS One 5(8): e12177.

Vriens, J., H. Watanabe, A. Janssens, G. Droogmans, T. Voets and B. Nilius (2004). "Cell swelling, heat, and chemical agonists use distinct pathways for the activation of the cation channel TRPV4." Proc Natl Acad Sci U S A 101(1): 396-401.

Waldmann, R. and M. Lazdunski (1998). "H(+)-gated cation channels: neuronal acid sensors in the NaC/DEG family of ion channels." Curr Opin Neurobiol 8(3): 418-424.

Wang, R. and G. R. Lewin (2011). "The Cav3.2 T-type calcium channel regulates temporal coding in mouse mechanoreceptors." J Physiol 589(Pt 9): 2229-2243.

Wetzel, C., J. Hu, D. Riethmacher, A. Benckendorff, L. Harder, A. Eilers, R. Moshourab, A. Kozlenkov, D. Labuz, O. Caspani, B. Erdmann, H. Machelska, P. A. Heppenstall and G. R. Lewin (2007). "A stomatin-domain protein essential for touch sensation in the mouse." Nature 445(7124): 206209.

Wetzel, C., S. Pifferi, C. Picci, C. Gok, D. Hoffmann, K. K. Bali, A. Lampe, L. Lapatsina, R. Fleischer, E. S. Smith, V. Begay, M. Moroni, L. Estebanez, J. Kuhnemund, J. Walcher, E. Specker, M. Neuenschwander, J. P. von Kries, V. Haucke, R. Kuner, J. F. Poulet, J. Schmoranzer, K. Poole and G. R. Lewin (2017). "Small-molecule inhibition of STOML3 oligomerization reverses pathological mechanical hypersensitivity." Nat Neurosci 20(2): 209-218.

Woller, S. A., K. A. Eddinger, M. Corr and T. L. Yaksh (2017). "An overview of pathways encoding nociception." Clin Exp Rheumatol 35 Suppl 107(5): 40-46.

Woo, S. H., V. Lukacs, J. C. de Nooij, D. Zaytseva, C. R. Criddle, A. Francisco, T. M. Jessell, K. A. Wilkinson and A. Patapoutian (2015). "Piezo2 is the principal mechanotransduction channel for proprioception." Nat Neurosci 18(12): 1756-1762.

Woo, S. H., S. Ranade, A. D. Weyer, A. E. Dubin, Y. Baba, Z. Qiu, M. Petrus, T. Miyamoto, K. Reddy, E. A. Lumpkin, C. L. Stucky and A. Patapoutian (2014). "Piezo2 is required for Merkel-cell mechanotransduction." Nature.

Wood, J. N. and N. Eijkelkamp (2012). "Noxious mechanosensation - molecules and circuits." Curr Opin Pharmacol 12(1): 4-8.

Woods, C. G., M. O. Babiker, I. Horrocks, J. Tolmie and I. Kurth (2015). "The phenotype of congenital insensitivity to pain due to the NaV1.9 variant p.L811P." Eur J Hum Genet 23(5): 561-563.

Woolf, C. J. and Q. F. Ma (2007). "Nociceptors-noxious stimulus detectors." Neuron 55(3): 353-364.

Wu, J., A. H. Lewis and J. Grandl (2017). "Touch, Tension, and Transduction - The Function and Regulation of Piezo lon Channels." Trends Biochem Sci 42(1): 57-71.

Yang, J., J. Zhang, H. Yang, K. Li, X. Lei and C. Xu (2016). "The potential role of Piezo2 in the mediation of visceral sensation." Neurosci Lett 630: 158-163.

Zappia, K. J., C. L. O'Hara, F. Moehring, K. Y. Kwan and C. L. Stucky (2017). "Sensory Neuron-Specific Deletion of TRPA1 Results in Mechanical Cutaneous Sensory Deficits." eNeuro 4(1).

Zhang, X. Y., J. Wen, W. Yang, C. Wang, L. Gao, L. H. Zheng, T. Wang, K. Ran, Y. Li, X. Li, M. Xu, J. Luo, S. Feng, X. Ma, H. Ma, Z. Chai, Z. Zhou, J. Yao, X. Zhang and J. Y. Liu (2013). "Gain-of-function mutations in SCN11A cause familial episodic pain." Am J Hum Genet 93(5): 957-966.

Zhao, Q., H. Zhou, S. Chi, Y. Wang, J. Wang, J. Geng, K. Wu, W. Liu, T. Zhang, M. Q. Dong, X. Li and B. Xiao (2018). "Structure and mechanogating mechanism of the Piezo1 channel." Nature 554(7693): 487-492.

Zimmerman, A., L. Bai and D. D. Ginty (2014). "The gentle touch receptors of mammalian skin." Science 346(6212): 950-954.

Zimmermann, K., A. Leffler, A. Babes, C. M. Cendan, R. W. Carr, J. Kobayashi, C. Nau, J. N. Wood and P. W. Reeh (2007). "Sensory neuron sodium channel Nav1.8 is essential for pain at low temperatures." Nature 447(7146): 855-858. 
Figure \& table legends

Table 1. The different types of cutaneous mechanoreceptors

Table 2. Complement of ion channels used in computational models of nociceptive neurons

Figure 1. Mechanotransduction in sensory neurons

A, Schematic representation of a C-fiber free nerve ending. Afferent mechanical signal generation involves different 'specialized' domains responsible from transducing mechanical stimuli into APs propagated to central synapses. These specialized structures are differentially populated with ion channels, involved in transduction, system gain and spike-generation.

B, Schematic drawing of a sensory neuron during recording of mechanically-activated currents. The soma of a cultured neuron is stimulated using an electrically driven mechanical probe while patch-clamp recorded in the whole-cell configuration.

C, Three types of MS currents, differing in their rate of adaptation, have been identified in cell bodies of sensory neurons. They are found to be expressed differentially in DRG neurons, classified from their cell somata diameter and mechanical threshold for activation. Piezo2 is the molecular correlate of rapidly-adapting MS currents, but ion channel(s) responsible for intermediately- and slowly-adapting MS currents, present in some nociceptors, is(are) still unknown. Displayed MS currents are representative for mouse DRG neurons at a holding potential of $-60 \mathrm{mV}$.

Figure 2. Modeling of C-type high threshold mechanoreceptors 
A, Scheme of the model structure, showing the main channel types and their subcellular distribution (e.g. transduction zone, peripheral axon, trunk-soma and central axon) together with the different recording sites. The model supports channels with Ohmic or Goldman-HodgkinKatz behavior and can simulate the time-course and steady-state conditions of ionic currents. B, Channel kinetics scheme (top inset) used to simulate the slow adapting MS current evoked by pressure clamp-like mechanical stimuli.

C-E, Steady-state IV relationships for Kdr (C), Nav1.8 and Nav1.9 (D) and TTX-S Nav (E) currents. Note the $-6 \mathrm{mV}(\# 1)$ and $-20 \mathrm{mV}$ (\#2) shift of Nav1.9 IV relationship used to depict the properties of Nav1.9 in mild and strong inflammatory conditions, respectively (D).

Figure 3. Modeling mechanical hypersensitivity in nociceptive neurons

A, Mechanical stimuli applied to the transduction zone and responses ( $\mathbf{B}$ to $\mathbf{F})$ of modeled HTMR representing normal, inflammatory and neuropathic conditions (as indicated). B-C, Shown are currents through slow adapting MS channels (B) and Nav1.9 channels (C) of the transduction zone.

D-F, Membrane potentials recorded from the transduction zone (D), peripheral axon at the junction to the $\mathrm{TZ}(\mathbf{E})$ and central ending $(\mathbf{F})$.

Inflammatory states were simulated by either $-6 \mathrm{mV}$ (inflammatory condition \#1) or $-20 \mathrm{mV}$ (inflammatory condition \#2) shift of Nav1.9 activation/inactivation kinetics (cf. IVs in Fig. 2C). The neuropathic condition was simulated by a $33 \%$ increase in the maximal conductivity of slow adapting MS channels mimicking post-lesional accumulation of channels near the TZ. 


\begin{tabular}{|c|c|c|c|c|c|c|}
\hline $\begin{array}{l}\text { Receptor } \\
\text { Subtype }\end{array}$ & $\begin{array}{l}\text { Associated } \\
\text { nerve fiber }\end{array}$ & Skin & $\begin{array}{l}\text { Ending } \\
\text { structure }\end{array}$ & Location & $\begin{array}{l}\text { Mechanical } \\
\text { stimulus }\end{array}$ & Response properties \\
\hline SAI-LTMR & $\Delta R$ & Glabrous & Merkel cell & Epidermis & Indentation & 111 \\
\hline SAII-LTMR & $A \beta$ & Glabrous & Ruffini & Dermis & Stretch & \\
\hline \multirow{2}{*}{ RAI-LTMR } & \multirow{2}{*}{$A \beta$} & Glabrous & $\begin{array}{l}\text { Meissner } \\
\text { corpuscle }\end{array}$ & $\begin{array}{l}\text { Dermal } \\
\text { papillae }\end{array}$ & Skin movement & \\
\hline & & Hairy & $\begin{array}{l}\text { Longitudinal } \\
\text { lanceolate } \\
\text { ending }\end{array}$ & $\begin{array}{l}\text { Guard/Awl- } \\
\text { Auchene hair } \\
\text { follicles }\end{array}$ & $\begin{array}{l}\text { Hair follicle } \\
\text { deflection }\end{array}$ & \\
\hline RAII-LTMR & $A \beta$ & Glabrous & $\begin{array}{l}\text { Pacinian } \\
\text { corpuscle }\end{array}$ & Dermis & Vibration & \\
\hline Aס̄-LTMR & $\mathrm{A} \delta$ & Hairy & $\begin{array}{l}\text { Lanceolate } \\
\text { ending }\end{array}$ & $\begin{array}{l}\text { Awl-Auchene, } \\
\text { Zigzag hair } \\
\text { follicles }\end{array}$ & $\begin{array}{l}\text { Hair follicle } \\
\text { deflection }\end{array}$ & \\
\hline C-LTMR & C & Hairy & $\begin{array}{l}\text { Lanceolate } \\
\text { ending }\end{array}$ & $\begin{array}{l}\text { Awl-Auchene, } \\
\text { Zigzag hair } \\
\text { follicles }\end{array}$ & $\begin{array}{l}\text { Hair follicle } \\
\text { deflection }\end{array}$ & \\
\hline HTMR & $A \beta / A \delta / C$ & $\begin{array}{c}\text { Glabrous } \\
\text { Hairy }\end{array}$ & $\begin{array}{l}\text { Free nerve } \\
\text { ending }\end{array}$ & $\begin{array}{l}\text { Epidermis } \\
\text { Dermis }\end{array}$ & Tissue injury & \\
\hline
\end{tabular}




\begin{tabular}{|c|c|c|c|c|c|c|c|c|c|}
\hline & $\begin{array}{c}\text { Scriven } \\
\text { (1981) }\end{array}$ & $\begin{array}{l}\text { Herzog et } \\
\text { al. (2001) }\end{array}$ & $\begin{array}{l}\text { Sheets et } \\
\text { al. (2007) }\end{array}$ & $\begin{array}{c}\text { Kouranova } \\
\text { et al. } \\
\text { (2008) }\end{array}$ & $\begin{array}{c}\text { Maingret } \\
\text { et al. } \\
(2008)\end{array}$ & $\begin{array}{c}\text { Choi \& } \\
\text { Waxman } \\
\text { (2011) }\end{array}$ & $\begin{array}{c}\text { Tigerholm } \\
\text { et al. } \\
\text { (2014) }\end{array}$ & $\begin{array}{c}\text { Petersson } \\
\text { et al. } \\
\text { (2014) }\end{array}$ & $\begin{array}{l}\text { Sundt et } \\
\text { al. (2015) }\end{array}$ \\
\hline $\begin{array}{l}\text { Nav1.9 } \\
\text { (TTX-R) }\end{array}$ & & + & & + & + & & + & + & \\
\hline $\begin{array}{l}\text { Nav1.8 } \\
\text { (TTX-R) }\end{array}$ & & & + & & + & + & + & + & \\
\hline $\begin{array}{c}\text { Nav } \\
\text { (TTX-S) }\end{array}$ & + & + & & + & & & & & \\
\hline $\begin{array}{l}\text { Nav1.7 } \\
\text { (TTX-S) }\end{array}$ & & & + & & & + & + & + & + \\
\hline $\mathrm{NaP}$ & & & & + & & & & & \\
\hline $\begin{array}{c}\text { Cav } \\
\text { (Ca-T) }\end{array}$ & + & & & & & & & & \\
\hline $\begin{array}{c}\text { Cav } \\
\text { (Ca-L) }\end{array}$ & & & & & & & & & + \\
\hline Kdr & + & + & + & + & + & + & + & + & + \\
\hline Ih & & & & + & & & + & + & \\
\hline KA & & & + & & & + & + & + & \\
\hline $\begin{array}{c}\text { Kv7 } \\
\text { (KM) }\end{array}$ & & & & & + & & + & + & + \\
\hline $\begin{array}{l}\mathrm{K}(\mathrm{Ca}) \\
\text { (K-SK) }\end{array}$ & + & & & & & & & & + \\
\hline $\mathrm{K}(\mathrm{Na})$ & & & & & & & + & + & \\
\hline $\begin{array}{c}\text { Na-K } \\
\text { pump }\end{array}$ & + & & & & & & + & + & \\
\hline $\begin{array}{c}\mathrm{Ca} \\
\text { pump }\end{array}$ & + & & & & & & & & \\
\hline
\end{tabular}


A Mechanical Low-threshold

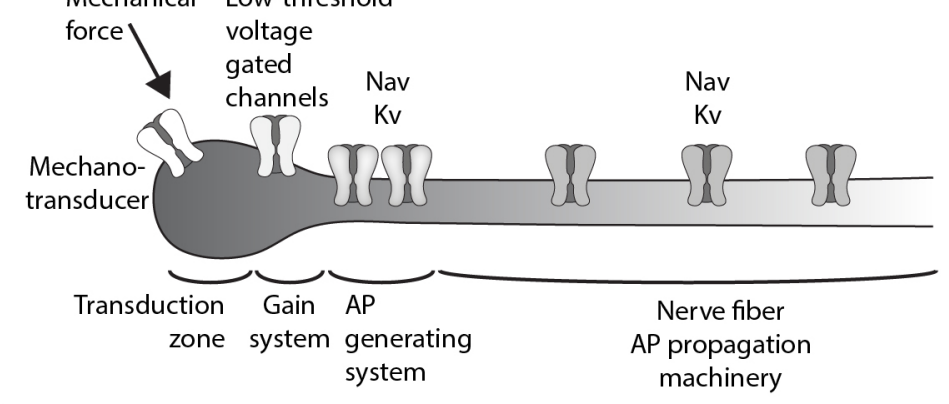

B

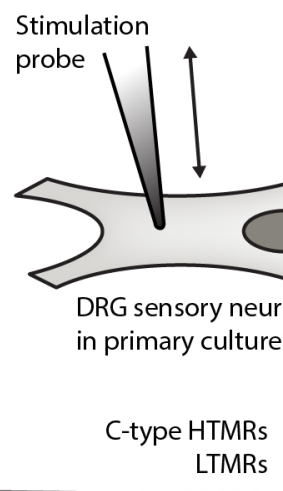

A $\beta$ LTMRs

A $\delta$ HTMRs

LTMRs

Soma diameter
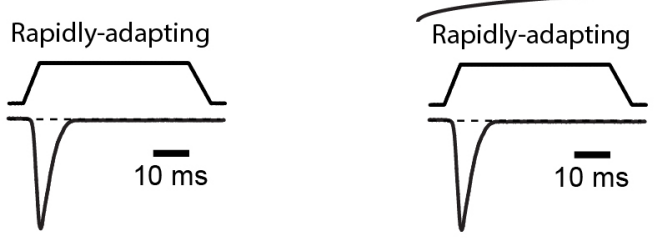

Intermediately-adapting
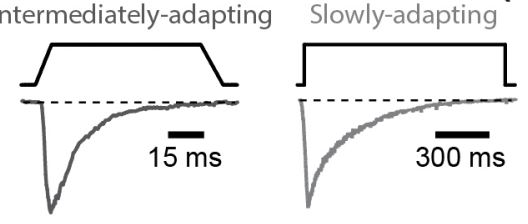

Activation threshold
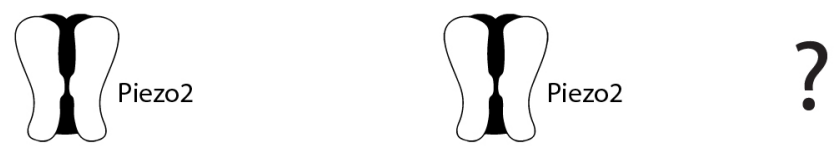

?

-Light touch

-Proprioception
-Mechanical

allodynia/hyperalgesia
Physiological

function
Mechanotransduction ion channel
Mechanical
Excitatory
mechanically-activated currents

-Nociception?

-Light touch?

-Proprioception?
-Nociception?

-Light touch?

-Proprioception?

(1)

ra



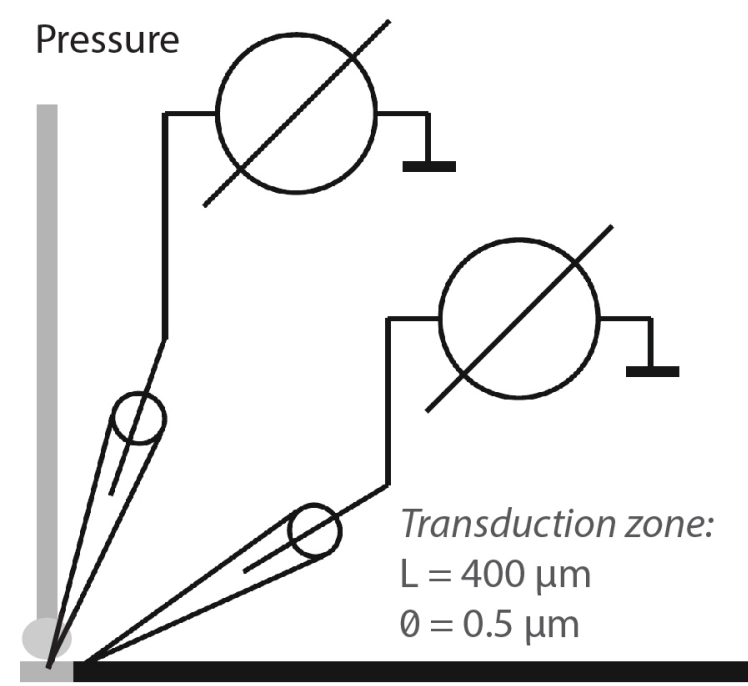

Transduction zone: Periph:

Transduction zone:

slow MS current

Nav1.9 Nav1.8

Kdr Leak
Periph:

Nav (TTX sensitive)

$\mathrm{Kdr}$

Leak
Soma:

$\mathrm{L}=25 \mu \mathrm{m}$

$0=30 \mu \mathrm{m}$
B

D

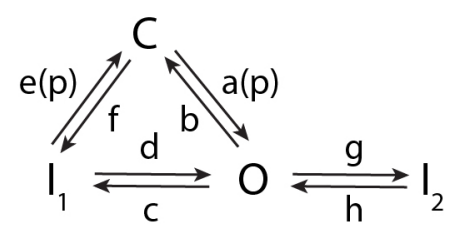

$+5$

$-60$
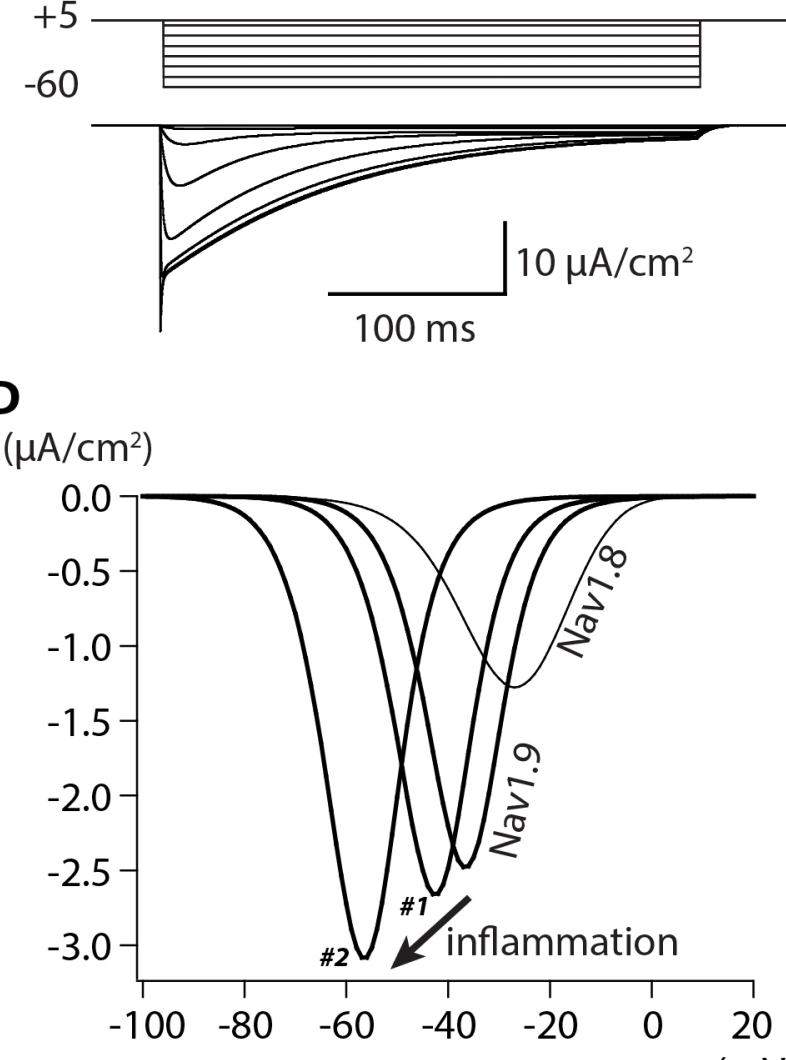

C

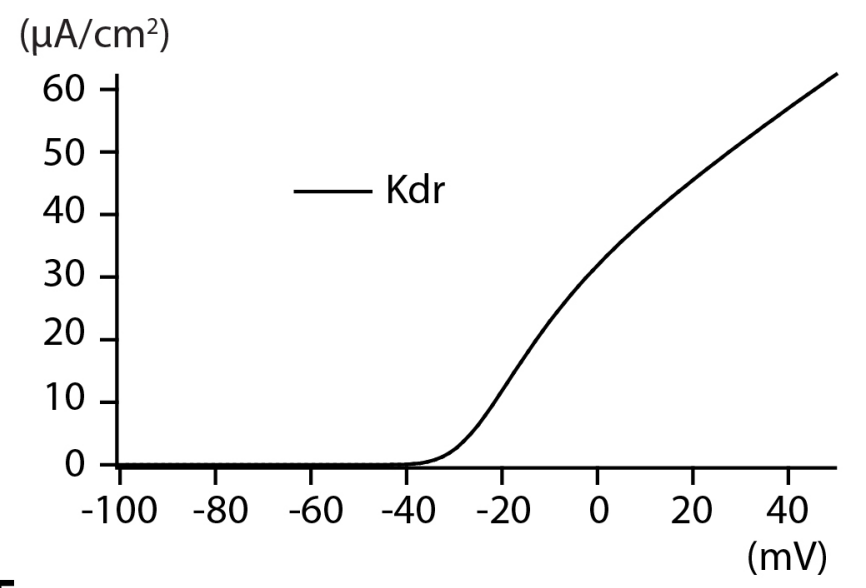

E

Soma, trunk, central:

Nav (TTX sensitive)

$\mathrm{Kdr}$

Leak
Central:

$\mathrm{L}=10 \mathrm{~mm}$

$0=0.5 \mu \mathrm{m}$

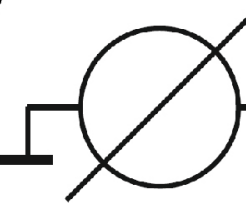

$\left(\mu \mathrm{A} / \mathrm{cm}^{2}\right)$

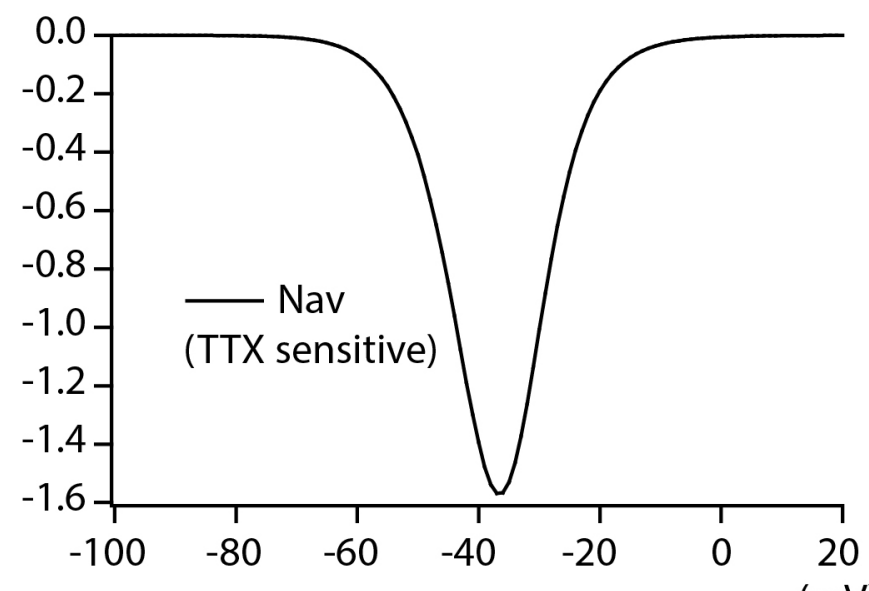
$(\mathrm{mV})$ 
Normal condition

Mechanical stimulus

B

Mechanosensitive current
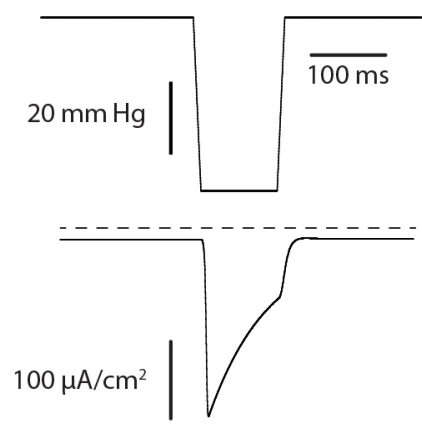

C

Nav1.9

current

\section{D}

Transduction zone

E

Peripheral fiber (200 $\mu \mathrm{m}$ away from transduction zone)

F Central
discharge
pattern
(30 mm
away from
transduction
zone)
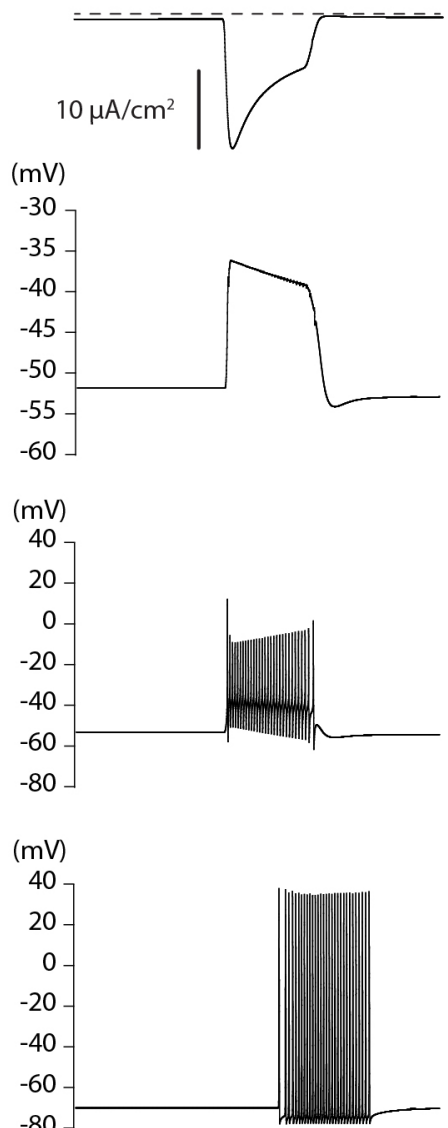

Inflammatory condition \# 1

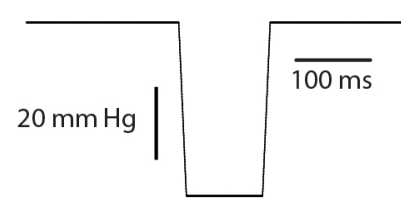

$100 \mu \mathrm{A} / \mathrm{cm}^{2}$
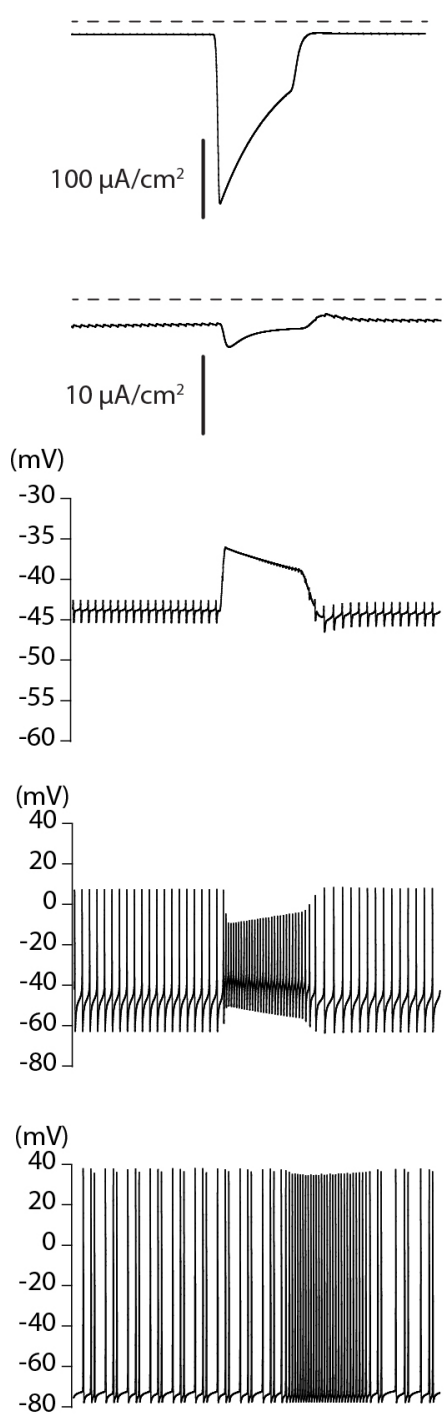

\section{condition \#2}
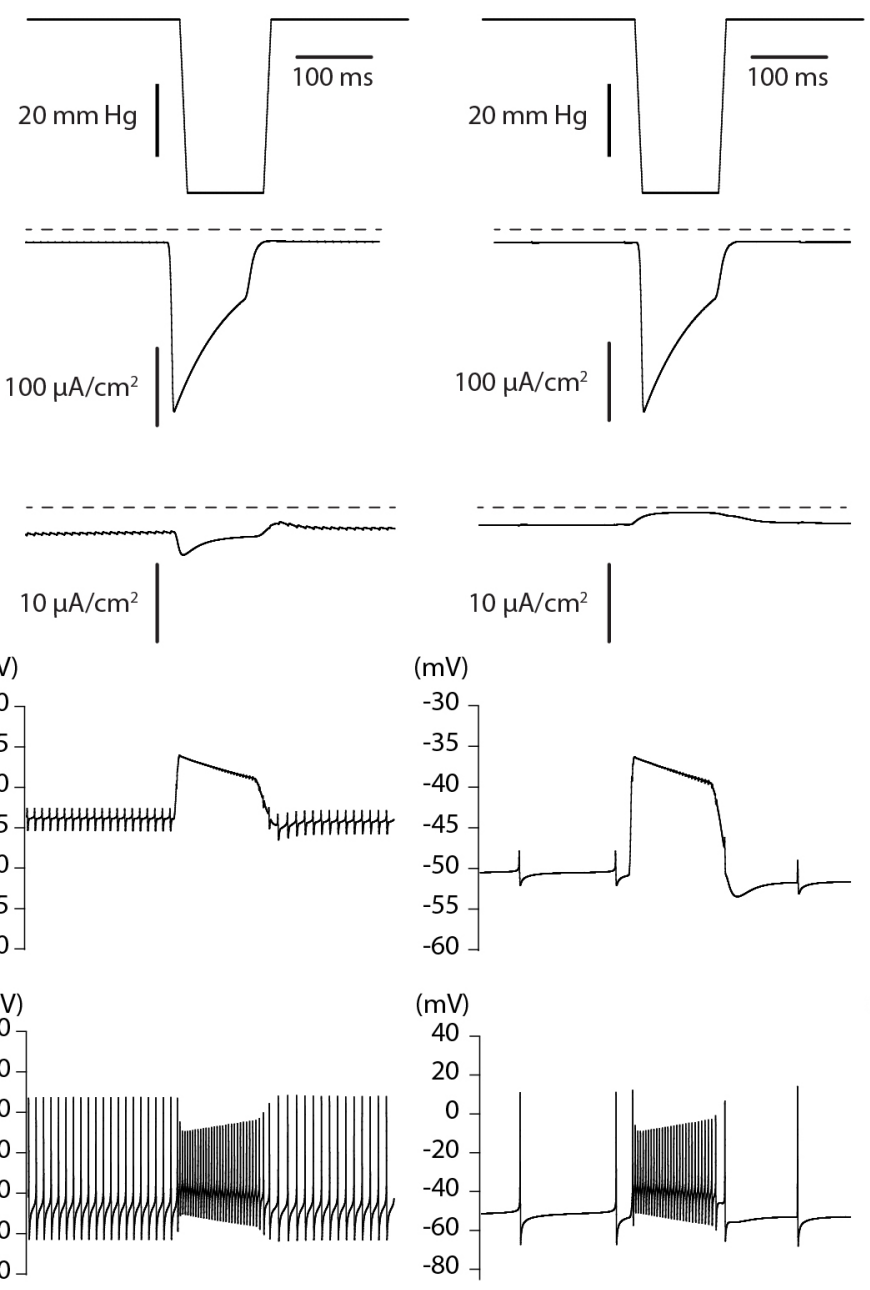

(mV)

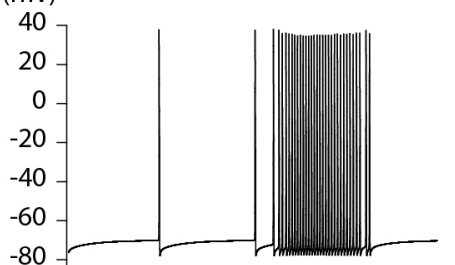

Neuropathic condition

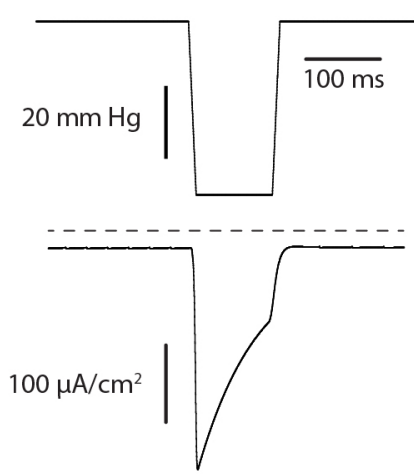

$10 \mu \mathrm{A} / \mathrm{cm}^{2}$

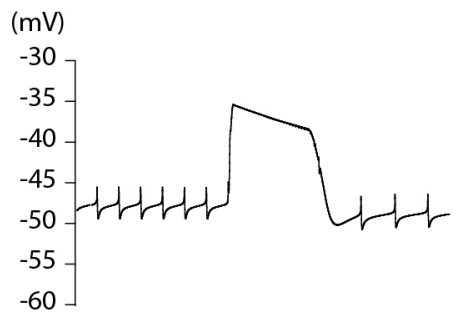

(mV)

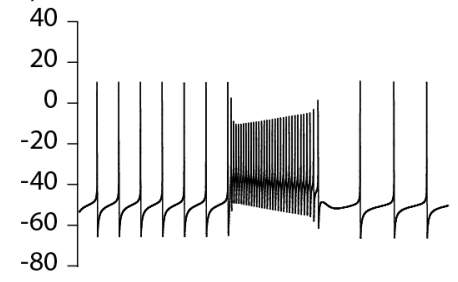

(mV)

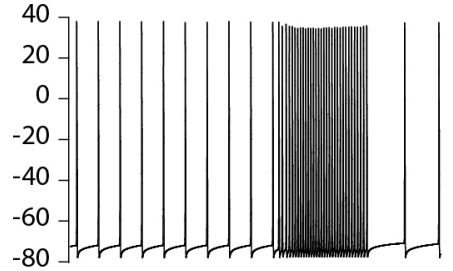

